\begin{tabular}{|c|l|}
\hline Title & Lagrangian ensemble model of Copepoda (Neocal anus cristatus) in the northwestern subarctic Pacific \\
\hline Author(s) & Terui, Takeshi; Kishi, Michio J.; Ueno, Hiromichi \\
\hline Citation & $\begin{array}{l}\text { Journal of OCeanography, 68(5), 727-741 } \\
\text { https://doi.org/10.1007/s10872-012-0130-z }\end{array}$ \\
\hline Issue Date & 2012-10 \\
\hline Doc URL & http://hdl.handle.net/2115/53419 \\
\hline Type & article (author version) \\
\hline File Information & Jo068_5_727-741.pdf \\
\hline
\end{tabular}

Instructions for use 


\section{Lagrangian ensemble model of Copepoda (Neocalanus cristatus) in the northwestern subarctic Pacific}

Takeshi Terui $^{\text {a, b, }}$, Michio J. KISHI ${ }^{\mathrm{c}, \mathrm{d}}$, Hiromichi Ueno ${ }^{\mathrm{c}}$

${ }^{a}$ Graduate School of Environmental Science, Hokkaido University, N10W5 Kitaku, Sapporo, Hokkaido 060-0810, Japan

${ }^{b}$ Core Research for Evolutional Science and Technology, Japan Science and Technology Agency, 5 Sanbancho, Chiyoda-ku, Tokyo 102-0075, Japan

${ }^{c}$ Faculty of Fisheries Sciences, Hokkaido University, Minatocho 3-1-1, Hakodate, Hokkaido 041-8611, Japan

${ }^{d}$ Research Institute for Global Change, JAMSTEC, Japan

*Corresponding author;

Tel.: +81-045-778-5666

Fax: +81-045-778-5706

E-mail: tk4terui@ees.hokudai.ac.jp (T. Terui) 


\section{Abstract}

A Lagrangian ensemble model describing the population dynamics of Neocalanus cristatus was developed. To describe the ecology of $N$. cristatus, life stage must be included in the model. For this purpose, a new zooplankton compartment, divided into nine life stages, was added to the North Pacific Ecosystem Model for Understanding Regional Oceanography (NEMURO). In addition, we introduced Lagrangian particles for the copepod population. Each Lagrangian particle represented a population of the same cohort of copepods with information on representative age, developmental stage, growth rate, structural weight, and food satiation. The new model revealed that surviving cohorts are only matched with the phytoplankton bloom after the nauplii stages. The model showed that the existing phytoplankton concentration when copepodites of $N$. cristatus appear in the surface water determines the development pattern of copepodite stages. The timing of the seasonal phytoplankton bloom depends on climate change, and a sensitivity analysis showed that the multiple spawning strategy through time has an important role in matching the unstable seasonal bloom cycle on a daily basis. The model including the cohorts can collaborate closely with weekly or monthly observations to reveal the rapid response of the marine ecosystem.

Keywords: Lagrangian ensemble model; Neocalanus cristatus; NEMURO; North Pacific Ocean; Zooplankton

\footnotetext{
Abbreviations:

NEMURO: North Pacific Ecosystem Model for Understanding Regional Oceanography; PDM: Population Dynamics Model; LEM: Lagrangian Ensemble Model; ZS: Small zooplankton (ZS); ZL: Large zooplankton; ZP: Predatory zooplankton; PS: Small phytoplankton; PL: Large phytoplankton; $\mathrm{NO}_{3}$ : Nitrate; $\mathrm{NH}_{4}$ : Ammonium; $\mathrm{Si}(\mathrm{OH})_{4}$ : Silicate; PON: Particulate organic nitrogen; DON: Dissolved organic nitrogen; Opal: Particulate organic silicate; SST: Sea surface temperature
} 


\section{Introduction}

Neocalanus species ( $N$. cristatus, $N$. plumchrus, and $N$. flemingeri), the dominant large grazing copepods in the subarctic Pacific (Miller et al. 1984; Vidal and Smith 1986; Mackas and Tsuda 1999), have annual life cycles, and they undergo an extensive ontogenetic vertical migration (Miller et al. 1984; Miller and Clemons 1988; Kobari and Ikeda 1999, 2001a, b). Eggs hatch in deep water, and the resultant nauplii develop into early copepodites during their upward migration from deep water to the surface (Miller et al. 1984; Miller and Clemons 1988). Growth and development occur in the surface water from early spring to early summer with feeding on phytoplankton and microzooplankton (Dagg 1993; Gifford 1993). However, maturation and egg production in Neocalanus take place at depths of 1000-2000 m during midsummer without feeding (Miller et al. 1984; Miller and Clemons 1988). Such life cycle strategies are ideally suited to large seasonal fluctuations in primary production (Kobari and Ikeda 2000). Considering their rapid growth and high biomass, Neocalanus species may constitute one of the greatest secondary production systems in the world's oceans (Kobari et al. 2003).

Kishi et al. (2001) included ontogenetic vertical migration into a numerical model, which showed that vertical migration played an important role in the transition of phytoplankton species during the spring bloom in the northwestern subarctic Pacific. Aita et al. (2003) and Kishi et al. (2007) developed the lower trophic-level ecosystem model NEMURO (North Pacific Ecosystem Model for Understanding Regional Oceanography), including the vertical migration of large zooplankton, and they developed a global three-dimensional (3-D) physicalbiological coupled model. They found that the transition of phytoplankton species responsible for the spring bloom is well reproduced by this model with vertical migration of zooplankton but is not simulated by the model without vertical migration.

Copepods, however, exhibit complex behavior, feeding on different prey and living at different depths during various developmental stages (Miller et al. 1984; Miller and Clemons 1988; Kobari and Ikeda 1999, 2001a, b). N. cristatus development is divided into the following developmental stages: the egg stage, represented as egg; the naupliar stages, as nauplii; five copepodite stages, represented as $C 1, C 2, C 3, C 4$, and $C 5$; and the adult stage, as adult, based on 
previously published observations (Kobari and Ikeda 1999; Saito and Tsuda 2000; Kobari et al. 2003). Moreover, Ikeda et al. (1990) classified C5 with a conspicuous amount of lipids as solid-type specimens. Ikeda (1990) also observed that solid-type C5 descends to depths of 1000-2000 m and enters diapause for several months. Terui and Kishi (2008) considered diapausing C5 to be a separate stage, solid, and they modeled structured growth dynamics of these nine stages of $N$. cristatus. This model was a population dynamics model (PDM) that included stage and age class within stage. This PDM can be used to model the dynamic interactions between a dominant zooplankton population and its prey (Carlotti and Radach 1996; Carlotti et al. 2000). Terui and Kishi (2008) represented the annual life cycle of $N$. cristatus, including ontogenetic migration and staged growth, and discussed the grazing impact of each developmental stage on lower trophic levels in the ecosystem. This PDM successfully described the annual life cycle of Neocalanus. The grazing impact on the lower trophic levels of the ecosystem was shown for small phytoplankton (PS) and large phytoplankton (PL). Early copepodite stages during the spring bloom grazed on PS without consuming PL. Therefore, PL biomass increases greatly in spring. Subsequently, individuals in the last copepodite stage may begin to prey mostly on PL. Terui and Kishi (2008) reported that copepodite stages in the surface water were induced to immediate metamorphosis in response to changes in the type of food available.

The mechanism of stage development included in this PDM was described as a certain number of individuals being transferred from the each age class in the same stage to the initial age class at the next stage. The number of transferred individuals was calculated from the age and the weight of each population. This mechanism can represent different developmental stages through different growth rates and ages. However, in this model, the transferred individuals were integrated into the initial age population of the next stage at the time of transition from each population. Therefore, the life history of a population born on a certain day could not be tracked from birth to death. Additionally, with respect to the egg-laying setting described by Terui and Kishi (2008), N. cristatus was assumed to produce eggs once, approximately 3 months after it matured. According to Saito and Tsuda (1999), N. cristatus has been shown to produce $76 \pm 19.3$ eggs five to seven times at intervals of 14.7 days at $2^{\circ} \mathrm{C}$. Copepods exhibit complex behavior, feeding on different prey and living in different cohorts (Miller et al. 1984; Miller and 
Clemons 1988, 1989; Kobari and Ikeda 1999; Kobari and Ikeda 2001a, b). The previously developed models cannot investigate the influence of the various birth dates for Neocalanus, each of which is associated with different conditions with respect to the feeding and duration of copepodites in the surface water.

To model large populations, Woods and Onken (1982) introduced the Lagrangian ensemble method, in which each population particle comprises a varying number of organisms. A Lagrangian Ensemble Model (LEM), in which one Lagrangian particle is formed by grouping the eggs produced at the same time by matured females, can be used to represent the population dynamics of copepods (Woods and Onken 1982; Carlotti and Wolf 1998; Carlotti et al. 2000). Each particle of the Lagrangian model represents a cohort of copepods, which means that one particle denotes a set of copepods with the same birth date. Each particle includes records that represent age, development stage, growth rate, structural weight, and food satiation. We can compare the differences among cohorts using the LEM.

The purpose of the present study was to develop a LEM for Neocalanus cristatus, describe differences in its growth depending on its cohorts, and discuss the effects of environment on its growth, stage length, and maturation.

\section{Method}

\subsection{Lagrangian Ensemble Model (LEM)}

To include the developmental stages of copepods, a LEM was coupled with NEMURO (North Pacific Ecosystem Model for Understanding Regional Oceanography; Kishi et al. 2007) (Fig. 1). NEMURO is based on nitrogen and silica flows with 11 compartments. These include three zooplankton compartments, small zooplankton (ZS), large zooplankton (ZL), and predatory zooplankton (ZP); two compartments for phytoplankton, small phytoplankton (PS), and large phytoplankton (PL); three compartments for nutrients, nitrate $\left(\mathrm{NO}_{3}\right)$, ammonium $\left(\mathrm{NH}_{4}\right)$, and silicate $\left[\mathrm{Si}(\mathrm{OH})_{4}\right]$; and other compartments for particulate organic nitrogen (PON), dissolved organic nitrogen (DON), and particulate organic silicate (Opal). ZS corresponds to ciliates and ZL corresponds to copepods exhibiting ontogenetic migration. ZP corresponds to gelatinous plankton, euphausiids (or krill) that are included as a predator of PL, ZL, and ZS. The 
equations, process formulations, and parameter values used in our model are similar to those of the original NEMURO (Kishi et al. 2007). In the present study, we divided ZL into two compartments, i.e., $N$. cristatus and the other large copepods. For the $N$. cristatus compartment, we introduced a LEM (Fig. 1). We calculated our model until it reached a steady state for analyzing continual $N$. cristatus life history and strategy under typical seasonal variation.

Our LEM was based on the description by Carlotti and Wolf (1998), who modeled Calanus finmarchicus, with each Lagrangian particle representing a cohort of identical individuals spawned on the same date and including information on birth date, weight, stage, age, and number. We described a similar Lagrangian particle for N. cristatus coupled with NEMURO (Fig. 1). The processes of ingestion, excretion, egestion, growth, mortality, predation, and reproduction for individuals were calculated from the state variables. Details of the processes used in this study are presented in section 2.3.

The biological processes (growth, mortality, predation, and transition of stages) were calculated using this individual information. The biomass of each particle can be calculated by multiplying the population density of the particle and the weight of an individual. We do not consider individual differences within each cohort because we want to investigate differences in growth depending on cohorts. The LEM is a carbon-based model, so converting between nitrogen units in NEMURO and carbon units in the LEM was necessary. We assumed that all phytoplankton compartments in NEMURO had a Redfield C/N ratio of 106/16. All parameters and regressions applied to the LEM were converted from nitrogen units to carbon units.

\subsection{Physical model}

To describe the ontogenetic vertical migration of $N$. cristatus, a simplified vertical two box model was used following Terui and Kishi (2008), i.e., a surface box representing the euphotic zone and a deep box representing the deep zone. NEMURO was calculated only in the surface box. $N$. cristatus was moving between these two boxes during its vertical migration. $N$. cristatus individuals

mainly spend their life in deep water without feeding (Kobari and Ikeda 1999; Saito and Tsuda 2000) except copepodites (C1-C5).

Sea surface temperature (SST), sea surface light intensity, and mixed layer 
depth (MLD) were given for the surface box. Equations and parameters for forcing in the original NEMURO are able to reproduce a classic North Pacific spring bloom scenario (Kishi et al. 2007; Terui and Kishi 2008), such as one might find at Station A7 $\left(41.5^{\circ} \mathrm{N}, 145.5^{\circ} \mathrm{E}\right)$ in the Oyashio region, off southeastern Hokkaido, Japan. We applied our model to Station A7. A periodic function is similar to the method of Terui and Kishi (2008), as shown in Fig. 2. The temperature in the $200-1500$ m layer was nearly constant at $2-3{ }^{\circ} \mathrm{C}$ (Kobari and Ikeda 1999; Yamaguchi et al. 2010). A laboratory experiment for eggs and nauplii for Neocalanus spp. was performed at $2{ }^{\circ} \mathrm{C}$ (Saito and Tsuda 2000). From these previous studies, the temperature in the deep box was fixed as a constant boundary condition $\left(2{ }^{\circ} \mathrm{C}\right)$.

The $\mathrm{NO}_{3}$ and $\mathrm{Si}(\mathrm{OH})_{4}$ concentrations in the deep box is set to be constant (World Ocean Atlas 1998: Antonov et al. 1998), and each concentration is given $25.0 \mu \mathrm{mol} \mathrm{N} \mathrm{L}{ }^{-1}$ and $35 \mu \mathrm{mol} \mathrm{Si} \mathrm{L}{ }^{-1}$. The thickness of the mixed layer increases (decreases) when the SST is lower (higher) than the deep water temperature (Ito et al. 2004). The exchange rate of $\mathrm{NO}_{3}$ and $\mathrm{Si}(\mathrm{OH})_{4}$ between the mixed layer and the bottom layer changes as a function of the stability defined by the difference in temperature between SST and the deep water temperature.

Neocalanus spp. do not have a diel feeding rhythm, and all immature copepodite stages for $N$. cristatus are concentrated in the surface water throughout the day (Tsuda and Sugisaki 1994). Therefore, we assume that the MLD does not affect $N$. cristatus particle movement between the surface box and deep box.

\subsection{Processes}

\subsubsection{Growth}

The growth of an individual of cohort $\mathrm{i}\left(\right.$ growth $_{i}$, in $\left.\mathrm{mg} \mathrm{C} \mathrm{ind}^{-1} \mathrm{day}^{-1}\right)$ is calculated

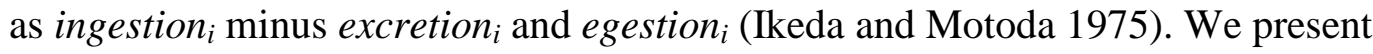
a detailed expression of ingestion ${ }_{i}$, egestion ${ }_{i}$, and excretion $_{i}$ in Table 1, and the formulation of each process is the same as for NEMURO except for excretion. The values of the parameters vary among stages and are shown, together with references, in Table 2.

$N$. cristatus is divided into nine developmental stages following the classification used by Terui and Kishi (2008). The nine stages are as follows: the 
egg stage, represented as egg; naupliar stages, as nauplii; five copepodite stages, $C 1, C 2, C 3, C 4$, and $C 5$; diapausing $\mathrm{C5}$, as solid; and the adult stage, as adult.

Ingestion represents the biomass obtained by feeding. Egestion represents the portion of ingested matter that is not assimilated. The assimilation efficiency (P6) of N. cristatus copepodites is 70\% (Ikeda and Motoda 1978; Kobari et al. 2003), and we assumed the same value for all stages. Egestion is $30 \%$ of the ingestion:

$$
\text { Egestion }_{\mathrm{i}}=0.3 \times \text { Ingestion }_{\mathrm{i}}
$$

where excretion is the metabolic rate. Ikeda et al. (2001) represented excretion through a multiple regression of water temperature and weight. We used their regression as follows:

$$
\ln (\mathrm{AE})=-2.769+0.711 \ln \left(\mathrm{W}_{\mathrm{i}}\right)+0.071 \times \mathrm{T}
$$

where AE is the amount of excretion of ammonia $\left(\mu \mathrm{g} \mathrm{N}\right.$ ind $\left.^{-1} \mathrm{~h}^{-1}\right), \mathrm{W}_{\mathrm{i}}$ is the carbon weight of an individual in cohort $\mathrm{i}\left(\mathrm{mg} \mathrm{C}\right.$ ind $\left.^{-1}\right)$, and $\mathrm{T}$ is the water temperature $\left({ }^{\circ} \mathrm{C}\right)$. The LEM used in this study is a carbon-based model, so converting between nitrogen units in $\mathrm{AE}$ and carbon units in excretion was necessary. We applied the Redfield $\mathrm{C} / \mathrm{N}$ ratio (6.6) to AE. Finally, we obtained the excretion converted to carbon weight as follows:

$$
\text { Excretion }_{\mathrm{i}}\left(\mathrm{W}_{\mathrm{i}}, \mathrm{T}\right)=\mathrm{AE} \times 6.6 \times 24 \div 1000 .
$$

In Eq. (3), the value 24 was used to convert AE from an hourly to a daily rate, and 1000 was used to convert from $\mu \mathrm{g}$ to $\mathrm{mg}$. We represented the relationship between weight and proportion of excretion to weight in Fig. 3 for $\mathrm{T}$ at $2{ }^{\circ} \mathrm{C}, 4{ }^{\circ} \mathrm{C}$, and $6{ }^{\circ} \mathrm{C}$. The proportion of excretion to weight is larger when the weight is smaller. Ingestion is a function of food density, water temperature, and weight of $N$. cristatus. No accurate data are available pertaining to the relationship between food concentration and ingestion rate of $N$. cristatus. Therefore, we adopted an Ivlev function that is widely used in other zooplankton dynamics models ( $\mathrm{f} 1$ in Table 1). This function was also used for ZL in NEMURO to represent dependence on the food concentration. Carlotti and Wolf (1998) and Batchelder et al. (2002) also used this equation.

The parameters used in $\mathrm{f} 1$ were the maximal ingestion rate $(\mathrm{P} 1)$, the limit of the food concentration (P2), and the Ivlev coefficient (P5). The method for obtaining P1 is explained in the next paragraph. P2 is the food concentration 
threshold below which copepodites stop feeding. P5 is the coefficient of the Ivlev function: the larger P5 is, the more rapidly the Ivlev function reaches the saturation point. The response to food concentration has not been clearly described (Liu et al. 2005). Therefore, we did not consider the threshold of the food concentration (P2), and the value of the Ivlev coefficient (P5) was set to be the same as the ZL value in NEMURO after converting units.

The temperature-dependent term of the ingestion rate is represented as $\mathrm{f} 2$ following a constant Q10 law, which is an index to describe the effect on biological rate processes after increasing the temperature by $10{ }^{\circ} \mathrm{C}$. We used a value of 1.75 for Q10, as estimated for $N$. cristatus by Vidal and Whitledge (1982); consequently, the parameter $\mathrm{P} 3$ in $\mathrm{f} 2$ has a value of $0.056{ }^{\circ} \mathrm{C}^{-1}$. To make the temperature-dependent term equal to 1 at $6^{\circ} \mathrm{C}, \mathrm{P} 4$ in $\mathrm{f} 2$ was set to 0.714 .

Terui and Kishi (2008) estimated P1 as a function of body weight based on Dagg (1993). However, Terui and Kishi (2008) demonstrated that maximum ingestion rates for early copepodites were overestimated. In this study, we calculated $\mathrm{P} 1$ by applying the maximum growth rate at $6{ }^{\circ} \mathrm{C}$, estimated by Vidal and Smith (1986), to the growth equation defined by Ikeda and Motoda (1985),

$$
\mathrm{P} 1=\max \text { growth rate/0.7 }- \text { excretion }_{\mathrm{i}}(\mathrm{IW}, 6) /(0.7 \times \mathrm{IW}) \text {, }
$$

where IW is initial carbon weight $\left(\mathrm{mg} \mathrm{C}\right.$ ind $\left.^{-1}\right)$ for each copepodite stage, shown in Table 2 together with max growth rate. The f1 becomes equal to P1 under a sufficient food concentration.

We next discuss feeding activity of $N$. cristatus. Terui and Kishi (2008) set the selectivity such that later copepodite stages could feed on larger plankton (i.e., PS was grazed upon by all immature copepodite stages, ZS was preyed upon by C3-C5, and PL was grazed upon by only C5). However, Liu et al. (2005) found that $N$. cristatus consumes ciliates and diatoms, which correspond to ZS and PL in NEMURO. Small particles ( $<5 \mu \mathrm{m})$, which correspond to PS in NEMURO, however, were not ingested (Liu et al. 2005). We set the feeding activity of $N$. cristatus such that all immature copepodite stages in the LEM fed on PL and ZS (Table 3). The feeding activity of ZL did not change from the original NEMURO. We do not include food selectivity based on the copepodite stage of ZL in our model. 


\subsubsection{Mortality and predation}

Simulating the population and individual model continuously for many years is difficult because the model generates incomputable high numbers of individuals as the result of reproduction (Carlotti and Wolf 1998; Carlotti et al. 2000). To solve this problem, we had to decrease the population density in each particle through mortality. In this LEM, one particle was generated when mature females reproduced, and the initial population density (ind $\mathrm{m}^{-3}$ ) of the generated particle was the total density of laid eggs. The population density was lowered by mortality and predation by ZP (predatory zooplankton).

No accurate data are available pertaining to the recruitment success of Neocalanus spp. Tracking the same cohort is difficult because Neocalanus spp. are always being diffused by ocean circulation. Mackas and Tsuda (1999) estimated the minimum mortality rate for solids and adults to be $0.0065 \mathrm{day}^{-1}$. We used this value as a constant mortality ratio (MorR),

$$
\text { Mortality of cohort i }=\text { MorR } \times \mathrm{N}_{\mathrm{i}} \times \mathrm{N}_{\mathrm{i}} \text {. }
$$

The formula follows NEMURO, and the term does not include mortality due to predation activity by ZP. We assumed death for C1-C5 to be due to starvation as well. If the growth rate remained below 0.03 for more than 14 days, MorR was changed to 1 . We did not apply starvation to eggs, nauplii, solids, and adults because they develop without feeding (Saito and Tsuda 2000). We also did not apply predation mortality to these because the impact of a predator in deep water is unclear. The relationships among mortality, starvation, and predation for each stage are shown in Table 3. ZL is preyed upon by ZP in NEMURO with the grazing rate GraZL2ZP of the original NEMURO (Kishi et al. 2007, their Eq. 15). We calculated the grazing rate for $\mathrm{C} 1-\mathrm{C} 5$ of $N$. cristatus (GraLEM2ZP) by applying a similar Ivlev function to the prey-predator relationship between $N$. cristatus and ZP. The applied Ivlev function has parameters similar to those in the original NEMURO (Kishi et al. 2007, their Eq. 15). The only difference from the original is that the biomass of $\mathrm{ZL}$ in Eq. 15 was replaced by the sum of biomasses of C1-C5. GraLEM2ZP is divided by each cohort to obtain cohort predation mortality:

Predation mortality of cohort $\mathrm{i}=\operatorname{GraLEM} 2 \mathrm{ZP} \times \mathrm{W}_{\mathrm{i}} \times \mathrm{N}_{\mathrm{i}} /\left(\sum\left(\mathrm{W}_{\mathrm{i}} \times \mathrm{N}_{\mathrm{i}}\right)\right.$. 


\subsubsection{Transition of stages}

Eggs, nauplii, solids, and adults develop without feeding in the deep box. After spending a specified time in a given stage (Table 2), they are immediately transferred to the next stage.

The reproduction and development of eggs and nauplii has been investigated in the laboratory at $2{ }^{\circ} \mathrm{C}, 4{ }^{\circ} \mathrm{C}$, and $6{ }^{\circ} \mathrm{C}$ (Saito and Tsuda 2000). In our model, we fixed the water temperature in the deep box, where $N$. cristatus enters diapause, at $2{ }^{\circ} \mathrm{C}$.

The stock of diapausing C5s is dominant from July through October below $250 \mathrm{~m}$ (Miller et al. 1984). The development period from C5 to adult is estimated roughly at 1-3 months (Kobari and Ikeda 1999). We assumed a 90-day duration for the solid stage.

The egg-laying period at $2{ }^{\circ} \mathrm{C}$ for a female of $N$. cristatus is estimated to be 91 days (Saito and Tsuda 2000). N. cristatus has been shown to produce $76 \pm$ 19.3 eggs on five to seven occasions at intervals of 14.7 days at $2{ }^{\circ} \mathrm{C}$ (Saito and Tsuda 2000). We focused on differences between cohorts and assumed that a single female of $N$. cristatus produced 76 eggs each of six times with an interval of 14.7 days during its adult stage. After laying eggs, the adult dies and sinks rapidly out of the deeper layer (Kobari et al. 2003). This adult biomass was removed from the LEM, with no feedback to NEMURO. We assumed the sex ratio to be 1:1 and that half of the adults spawned. Therefore, the egg production by each cohort was calculated by multiplying the mean batch size (76) by the sex ratio (0.5) and population density of each cohort:

Egg production of cohort $\mathrm{i}$ for one spawning $=76 \times 0.5 \times \mathrm{N}_{\mathrm{i}}$.

After the eggs were spawned, they hatched into n0auplii in 5.7 days at $2{ }^{\circ} \mathrm{C}$. Saito and Tsuda (2000) described the relationship between temperature and development time from hatching (nauplii) to $\mathrm{C} 1$ as the widely accepted Bělehrádek equation:

$$
\mathrm{D}_{\mathrm{CI}}=17068 \times(\mathrm{T}+14.7)^{-2.05},
$$

where $\mathrm{D}_{\mathrm{CI}}$ is the development time from nauplii to $\mathrm{C} 1$ (days) and $\mathrm{T}$ is the water temperature $\left({ }^{\circ} \mathrm{C}\right)$. According to this function, nauplii molting time is 53.2 days at $2{ }^{\circ} \mathrm{C}$. 
As described above, a single female produces 76 eggs at six times separated by 14.7 days, but many cohorts exist and the spawning process continues on other 14.7 day cycles.

The mean egg-hatching success rate of $N$. cristatus is $81 \%$ (Saito and Tsuda 2000); thus, we set the success rate to be $81 \%$ (i.e., $81 \%$ of 76 eggs hatched). The carbon content of copepods was assumed to be a median value (45.4\%) based on the reported range of 25.9-64.8\% of dry weight (Omori 1970; Miller 1993; Oh et al. 1993). The initial weights of the different stages from egg to adult were determined based on observations reported by Kobari et al. (2003). When the weight of $\mathrm{C} 1-\mathrm{C} 5$ copepods reached the initial weight of the next stage (X in Table 2), the copepods started molting to the next stage. $\mathrm{X}$ was set to IW for the next stage.

\subsubsection{Feedback to NEMURO}

The processes linking the $N$. cristatus LEM to NEMURO are presented in Table 4. The total ingestions by $N$. cristatus of ZS and PL are represented as GRZS2LEM and GRPL2LEM, respectively, and these terms are subtracted respectively from the ZS and PL differential equations. The sums of egestion and excretion of $N$. cristatus are described as EgeLEM and ExcLEM, respectively, and are added respectively to the $\mathrm{PON}$ and $\mathrm{NH}_{4}$ equations. MorLEM is the sum of dead copepodite biomass due to mortality (MorR) and reproduces PON. MorLEM does not include the dead biomass of eggs, nauplii, solids, or adults because these stages live in the deep box.

\subsubsection{Initial condition of the LEM}

We add 76 individual eggs each day during the first year of the simulation. The model was solved numerically with an Euler forward scheme with a time-step of 1 $\mathrm{h}$, beginning on 1 February. This time-step is the same as for the original NEMURO, and it provides sufficient resolution for the model. The model was run for 50 years. The final state can be regarded to be an equilibrium state showing a steady annual cycle. 


\section{$3 \quad$ Results}

\subsection{Total number of $N$. cristatus}

Figure 4 shows the seasonal variation in the biomass of the biological compartments from NEMURO (PS, PL, ZS, ZP, ZL, and N. cristatus) in the surface box.

Figure 5 shows the annual cycle of the total numbers (sum of all cohorts) for each stage. Eggs produced by overwintered adults appeared in the lower layer from the middle of December to late April (Fig. 5a).

Nauplii appeared 6 days after eggs were spawned. The number of nauplii reached its maximum at the end of March. This number exceeded that of eggs because egg production and the transfer from eggs to nauplii continued at the same time from January until April. The nauplii stage lasted longer than that of eggs; therefore, the numbers of nauplii accumulated.

Precocious nauplii were transferred to the $\mathrm{C} 1$ stage in the middle of February (Fig. 5b). The number of $\mathrm{C} 1$ individuals from the beginning of March to 20 April was almost constant because the decrease resulting from mortality due to starvation and the increase through recruitment were equivalent. However, the number of $\mathrm{C} 1$ increased from 20 April to 14 May because these do not die by starvation. $\mathrm{C} 1$ copepods began to transfer to the $\mathrm{C} 2$ stage in the middle of May, when their body weight reached a sufficient level. The transfer among stages occurred rapidly through stages $\mathrm{C} 2-\mathrm{C} 4$, and the earliest $\mathrm{C} 5$ appeared on 26 July. C5 individuals in surface water began their vertical migration to deep water in early September, and the earliest solid appeared at this time (Fig. 5a). Recruitment to the adult stage began in early December.

As shown in Fig. 5, C1 appeared at the surface before the PL bloom, which corresponds with field observations (Kobari and Ikeda 1999). Surviving C1 individuals then matured and were immediately transferred to C2. However, C2 individuals became less abundant in early June due to predation, mainly by ZP. Therefore, the maximum number of individuals decreased drastically from $\mathrm{C} 2$ to C3 (Fig. 5).

In the deep water, the number of solids reached its maximum from late September through November. The solids then began to molt to adulthood in December (Fig. 5a). According to the results of Kobari and Ikeda (1999) in the 
western subarctic Pacific, C5 individuals migrate below $500 \mathrm{~m}$ from July through August, enter diapause, and then molt to adulthood after September, which coincides with our results.

\subsection{Total biomass of $N$. cristatus}

Figure 6 shows the biomass of copepods (sum in two boxes) obtained by multiplying the individual body weight by population density. Table 5 shows the monthly mean PL, ZS, temperature, and growth rate associated with each copepodite stage. The growth rates were calculated for the time duration when the population particles were alive.

Maturation from solids to adults continued from December to January, and the solid and adult stages dominated the copepod's biomass from October to early April. The next generation of copepodite stages appeared in April.

Simultaneously, the proportion of adults decreased due to spawning and death due to reaching the end of their life span. The total biomass began to increase from the middle of May, as the copepodites began to feed. The total biomass showed its first peak in the middle of July. The biomass in this season was composed mainly of $\mathrm{C} 4$ individuals (Figs. 5b and 6). C5 individuals dominated in August.

When C5 individuals began diapausing into solids, their biomass was transferred from the surface box to the deep box (Fig. 6). Total biomass was occupied by solids, which do not feed in the deep water, from October. The decrease in biomass was small during the solid stage because prey mortality does not play a role. Solids transferred to adults in the lower layer and spent almost 6 months there. This vertical migration of copepods represents a significant carbon flux, as noted by Kobari et al. (2003).

\subsection{Duration of copepodite stages}

The LEM successfully reproduced the continual seasonal variation under the ecosystem based on a classic North Pacific scenario. In this section, we compare the growth histories among typical cohorts and discuss environmental effects (PL, ZS, and temperature) on their growth, stage length, and maturation. 
Table 6 shows the growth history of population particles for a typical cohort. The average growth rates for surviving populations are within the range of observations described by Vidal and Smith (1986). The population particle born on 1 January appeared in surface water on 28 February as C1. However, both the food concentration and temperature were low at this time (Figs. 2, 4), and this particle died due to starvation (growth rate is calculated for the duration of the living organism). Figure 7 shows the variability in the growth rates of the four surviving cohorts described in Table 6.

Population particles born from 22 February to 7 April completed their life cycle (Table 6). The particle born on 22 February developed to the $\mathrm{C} 1$ stage on 20 April, and it matured to solids on 7 September. The particle born on 3 March developed to $\mathrm{C} 1$ on 29 April, and it matured to solids on 9 September. A 9-day difference existed between these birth dates. However, this difference was shortened to 2 days when these particles matured into solids. The duration of the C1 stage in the particle born on 3 March was 7 days shorter than that in the particle born on 22 February.

The initial growth rate of $\mathrm{C} 1$ born on 22 February was less than that of $\mathrm{C} 1$ born on 3 March (Fig. 7a, b). This difference was caused by the PL biomass. As shown in Fig. 6, the PL bloom began in May and the increased biomass brought about the higher growth rate of the $\mathrm{C} 1$ born on 3 March.

The population particle born on 7 April appeared in surface water on 4 June (Table 6). This date is after the peak of PL biomass (Fig. 4). When we compared the duration of copepodites between the particle born on 17 March and that born on 7 April, the latter was 2 days longer than the former. The mean growth rate of $\mathrm{C} 1$ born on 17 March was roughly twice that of $\mathrm{C} 1$ born on 7 April (Fig. 7c, d). The initial growth rate of $\mathrm{C} 1$ born on 17 March was high, and the form of the growth curve was increasing (Fig. 7c). However, the form of the growth curve of $\mathrm{C} 1$ born on 7 April was parabolic (Fig. 7d). This difference was caused by PL biomass. As shown in Fig. 4, PL biomass decreased until 22 June and this decrease brought about the lower growth rate of $\mathrm{C} 1$ born on 7 April. However, the duration of C2 born on 17 March was longer than that of $\mathrm{C} 2$ born on 7 April. This can also be explained by the difference in PL biomass when these transferred from $\mathrm{C} 1$ to $\mathrm{C} 2$. 


\subsection{Development pattern}

We produced a bar chart showing the duration of copepodite stages of the surviving cohort based on their birth date (Fig. 8). The particles were divided using their birth date into three groups.

The first group included particles born between 22 February and 10 March. These particles developed to the C1 stage before the PL bloom in April. When these particles appeared in surface water, the food concentration and temperature were low (Figs. 2, 4), with a mean PL of $32.2 \mathrm{mg} \mathrm{C} \mathrm{m}^{-3}$ and temperature of $3.4{ }^{\circ} \mathrm{C}$ (Table 5). The excretion rate in $\mathrm{C} 1$ individuals under these conditions was $0.066 \mathrm{day}^{-1}$, and the ingestion rate required to mature without starvation was calculated as $0.137 \mathrm{day}^{-1}$. The food concentration required to continue the life cycle was $83.5 \mathrm{mg} \mathrm{C} \mathrm{m}^{-3}$. In April, earlier population particles had to wait for the food concentration to improve by exhibiting a lower growth rate (Fig. 7a). As the PL bloom began in May (Fig. 4), the environment for the copepodites improved each day. The duration of copepodites was therefore shorter when they appeared later because prey density increased due to the spring bloom (Table 6, Fig. 8).

The second group consisted of particles born from 11 March to 23 March. This group developed to the $\mathrm{C} 1$ stage under bloom. No difference was observed in growth rates among the particles in the group. The excretion rate of $\mathrm{C} 1$ individuals in May was $0.075 \mathrm{day}^{-1}$, and the ingestion rate required to avoid starvation was calculated to be $0.150 \mathrm{day}^{-1}$. The total food concentration required was $81.0 \mathrm{mg} \mathrm{C} \mathrm{m}^{-3}$, and the mean PL in May was $121.6 \mathrm{mg} \mathrm{C} \mathrm{m}^{-3}$. Thus, the food concentration was sufficient for $\mathrm{C} 1$ to mature without starvation.

The third group consisted of particles born from 24 March to 7 April. This group developed to the $\mathrm{C} 1$ stage after PL decreased, and the growth rate of this group decreased over time. The growth rate of $\mathrm{C} 1$ between the end of May and end of June was below 0.03 day $^{-1}$ (Fig. 7b). Therefore, the duration became longer because the phytoplankton density was beginning to decrease (Table 6, Fig. 8). 


\section{Discussion}

Kobari and Ikeda (1999) reported that copepodites were observed during February and June in 1997, while they appeared from April to October in our model (Fig. 5). This difference exists because the PL bloom in NEMURO began in May, whereas field observations show that it actually begins in March (Kobari and Ikeda 1999). Hence, copepodite growth began 2 months later in the model. The growth characteristics of these copepodite stages corresponded to variations in PL biomass.

Liu et al. (2005) reported that total consumption under non-bloom conditions is $10.0 \mu \mathrm{g} \mathrm{C}$ ind $^{-1}$ day $^{-1}$ and that it averages $21.4 \mu \mathrm{g} \mathrm{C}$ ind $^{-1}$ day $^{-1}$ under bloom conditions. However, they estimated nutritional demand to be between 40 and $140 \mu \mathrm{g} \mathrm{C}$ ind ${ }^{-1}$ day $^{-1}$ and concluded that the consumption rates were inadequate to meet nutritional demands for growth and metabolism. The consumption rate of $\mathrm{C} 1$ born on 17 March in our model is $42.3 \mu \mathrm{g} \mathrm{C}$ ind $^{-1} \mathrm{day}^{-1}$, which is within the range of the estimate reported by Liu et al. (2005).

Kobari et al. (2003) found that C4 and C5 appeared at the same time. Our results do not coincide with their observations. Mean PL biomass in July was 66.3 $\mathrm{mg} \mathrm{C} \mathrm{m}{ }^{-3}$, but mean PL biomass in August was $50.9 \mathrm{mg} \mathrm{C} \mathrm{m}^{-3}$ (Table 5). When C5 appeared in the surface water in August, the food concentration was lower than in July, when C4 was dominant. The mean growth rate of C4 in July was $0.066 \mathrm{day}^{-1}$, but that of C5 in August was 0.047 day $^{-1}$ (Table 5). The growth rate of copepodites in our model declined mainly as a result of decreasing food concentration from July through August.

Figure 8 shows the relationship between the duration of copepodite stage and birth date. Particles that appear in surface water before the PL bloom die due to food shortages and low temperature (Table 5). If particles survive until the PL bloom, they may continue their life cycle. Their duration is shortened by the improving food environment and the growth of these particles catches up with the earlier particles.

Different birth dates resulted in differences in growth rate patterns (Fig. 7). If the temperature and food concentration were poor for $N$. cristatus, survival would be impossible. In particular, the food availability during the $\mathrm{C} 1$ stage is important for developmental success. To survive, the growth rate must be more than $0.03 \mathrm{mg} \mathrm{C}$ ind $^{-1}$ day $^{-1}$. When the temperature is $6{ }^{\circ} \mathrm{C}$, the $\mathrm{f} 2$ value is 1 . We 
can easily calculate the lowest ingestion value for survival. To satisfy the condition, the ingestion rate of the initial $\mathrm{C} 1$ individuals needed to develop (0.002 $\mathrm{mg} \mathrm{C}$ ind $^{-1}$ ) is 0.156 day $^{-1}$ at $6{ }^{\circ} \mathrm{C}$. Thus, the total food concentration required by the initial $\mathrm{C} 1$ is $167.1 \mathrm{mg} \mathrm{C} \mathrm{m}^{-3}$, and PL+ZS only surpassed this value in May (Table 5, Fig. 4). The food concentration required by $\mathrm{C} 1$ decreases with growth because the excretion rate decreases with increasing copepodite weight (Fig. 3). For $\mathrm{C} 1$ that appear before 19 April or after 5 June, the growth rate was below 0.03 $\mathrm{mg} \mathrm{C}$ ind ${ }^{-1}$ day $^{-1}$ continuously for 14 days (Table 6), so these could not survive. Zooplankton in boreal waters must match their life cycle to the seasonal production cycle (e.g., Conover and Siferd 1993; Atkinson 1998).

In our model, the population particle (cohort) born on 22 February produced its eggs on 21 December, 5 and 19 January, 3 and 18 February, and 4 March (6 times). Only the particle born on 4 March matched the phytoplankton bloom. Mismatched particles might be able to survive if the seasonal phytoplankton bloom occurs early.

We performed additional experiments to address the above matchmismatch hypothesis and corresponding changes in water temperature. Figure 9 shows the sensitivity to forcing by surface temperature, which was increased or decreased by $1{ }^{\circ} \mathrm{C}$ after the model reached a stable state. The model was transited to a quasi-steady state. It represented the disturbance of the environment, and we were able to investigate how N. cristatus sustained a continuous life history under an unstable environment. When temperature was increased, the PL bloom started 19 days earlier than under the standard condition (Fig. 9a). When the temperature was decreased, however, the PL bloom started 16 days later than under the standard condition (Fig. 9a). As a result, the accumulated copepodite biomass in the surface water shifted corresponding to the shift in food availability (Fig. 9b). We tracked the growth rate of the particle born on 22 February (Fig. 9c). This particle could not survive when the temperature was decreased because its duration when its growth rate is less than 0.03 continues for more than 14 days. However, when the temperature was increased, this particle finished its life cycle without any food shortage. Particles born before 22 February can also survive in the warmer case. The timing of the seasonal productivity cycle depends on climate change, and the sensitivity analysis shows that the multiple spawning 
strategy over long periods has an important role in matching unstable seasonal production cycles.

Under bloom conditions, $N$. cristatus grazes on diatoms with a low filtering rate and exhibits a high growth rate (Liu et al. 2005). Kobari and Ikeda (1999) observed the maximum number of C4 and C5 individuals at the same time under bloom conditions. These observations show that $N$. cristatus can mature in a short period of time if sufficient food is available. In our model, the maximum ingestion rate (P1) was estimated from the growth rate described by Vidal and Smith (1986), and copepodite stages do not complete under bloom conditions. The average food consumption by the copepodites with the fastest growth rate (born on $17 \mathrm{March}$ ) was $42.3 \mu \mathrm{g} \mathrm{C}$ ind ${ }^{-1}$ day $^{-1}$, and the duration of the copepodites was 127.3 days. Kobari and Ikeda (1999) estimated the duration of copepodites to be between 2 and 6 months. Saito and Tsuda (2000) estimated this value to be between 44 and 72 days. To complete all copepodite stages in 2 months in our model, PL+ZS must be one and one-half times larger than the value in the present model. In this case, the average growth rate would be $0.129 \mathrm{day}^{-1}$, and the food consumption would be $114.5 \mu \mathrm{g} \mathrm{C}$ ind $^{-1}$ day $^{-1}$. The PL concentration based on results from NEMURO reached $160 \mathrm{mg} \mathrm{C} \mathrm{m}^{-3}$ in the present model. However, observational data indicate much higher values (Shinada et al. 2001), which suggests that NEMURO should be modified from the original parameters or number of compartments.

We performed additional experiments to check the above idea. Figure 10 shows the sensitivity to the maximum ingestion rate (P1), which is 1.5 and 2 times higher than the value in the present model. The experiment represented the variability in the individual weights of the four surviving cohorts described in Table 6. If the maximum ingestion rate is doubled, the duration of copepodites is shortened and copepodite stages complete in 2 months under bloom conditions. The maximum ingestion rate of $N$. cristatus might actually have an even higher value.

In the northern Pacific, various individuals are born on different dates. However, these may mature at the same time under bloom conditions, as we suggest in Fig. 8. The present model can represent different growth rates depending on different birth dates using a Lagrangian model of zooplankton coupled with a lower trophic ecosystem model and a physical model. A 3-D 
model will be required to explain dynamic features, such as horizontal advection during egg and nauplii stages in the deeper ocean and copepodite stages at the sea surface. 


\section{Acknowledgements}

We would like to thank Dr. A. Yamaguchi of the Graduate School of Fisheries Sciences of Hokkaido University and Dr. T. Kobari of the Faculty of Fisheries of Kagoshima University for many useful insights, discussions and suggestions about zooplankton ecology. We were grateful to Dr. S. Montani and Dr. I. Kudo in the Graduate School of Fisheries Sciences of Hokkaido University for reading of the manuscript. The courteous comments and suggestions of anonymous reviewers markedly benefited the presented product. This research was a contribution to the "Marine Environmental Simulation Study for Future Projection of Marine Ecosystems" in the Core Research for Evolutional Science and Technology (CREST) promoted by the Japan Science and Technology Agency (JST), and also partially supported by the Green Network of Excellence (GRENE) Arctic Climate Change Research Project promoted by the National Institute of Polar Research. 


\section{References}

Aita MN, Yamanaka Y, Kishi MJ (2003) Effects of ontogenetic vertical migration of zooplankton on annual primary production - using NEMURO embedded in a general circulation model. Fish Oceanogr 12: 284-290. doi:10.1046/j.13652419.2003.00261.x

Antonov JI, Levitus S, Boyer TP, Conkright ME, O’Brien TD, Stephens C (1998) World ocean atlas 1998, vol 2. Temperature of the Pacific Ocean. NOAA atlas, NESDIS 28. US Government Printing Office, Washington, DC, pp 166 Atkinson A (1998) Life cycle strategies of epipelagic copepods in the Southern Ocean. J Marine Syst 15: 289-311. doi:10.1016/S0924-7963(97)00081-X Batchelder HP, Edwards CA, Powell TM (2002) Individual-based models of copepod populations in coastal upwelling regions: implications of physiologically and environmentally influenced diel vertical migration on demographic success and nearshore retention. Prog Oceanogr 53: 307-333. doi:10.1016/S00796611(02)00035-6

Carlotti F, Radach G, (1996) Seasonal dynamics of phytoplankton and Calanus finmarchicus in the North Sea as revealed by a coupled one-dimensional model. Limnol Oceanogr 41: 522-539.

Carlotti F, Wolf K (1998) A Lagrangian ensemble model of Calanus finmarchicus coupled with a 1D ecosystem model. Fish Oceanogr 7: 191-204.

doi:10.1046/j.1365-2419.1998.00085.x

Carlotti F, Giske J, Werner F (2000) Modeling zooplankton dynamics. In: Harris R, Wiebe P, Lenz J, Skjoldal HR, Huntley M (eds) ICES Zooplankton Methodology Manual. Academic Press, San Diego, pp. 571-667 Conover RJ, Siferd TD (1993) Dark-Season Survival Strategies of Coastal Zone Zooplankton in the Canadian Arctic. Arctic 46: 303-311.

Dagg M (1993) Sinking particles as a possible source of nutrition for the large calanoid copepod Neocalanus cristatus in the subarctic Pacific Ocean. Deep Sea Res I 40: 1431-1445. doi:10.1016/0967-0637(93)90121-I

Gifford DJ (1993) Protozoa in the diets of Neocalanus spp. in the oceanic subarctic Pacific Ocean. Prog Oceanogr 32: 223-237. doi:10.1016/00796611(93)90015-6 
Ikeda T, Motoda S (1975) An approach to the estimation of zooplankton production in the Kuroshio and adjacent regions. In: Morton B (eds), Special Symposium on Marine Sciences. Pacific Science Association, Hong Kong, pp. 24-28.

Ikeda T, Motoda S (1978) Estimated zooplankton production and their ammonia excretion in the Kuroshio and adjacent seas. Fish Bull 76: 357-366.

Ikeda T, Hirakawa K, Kajihara N (1990) Some characteristics of a coldwater copepod Calanus cristatus from regions of the Japan Sea covered by the Tsushima warm current. Bull Japan Sea Natl Fish Res Inst 40: 51-65.

Ikeda T, Kanno Y, Ozaki K, Shinada A (2001) Metabolic rates of epipelagic marine copepods as a function of body mass and temperature. Mar Biol 139: 587596. doi:10.1016/0079-6611(93)90015-6

Kishi M, Motono H, Kashiwai M, Tsuda A (2001) An ecological-physical coupled model with ontogenetic vertical migration of zooplankton in the Northwestern Pacific. J Oceanogr 57: 499-507. doi:10.1023/A:1021517129545 Kishi MJ, Kashiwai M, Ware DM, Megrey BA, Eslinger DL, Werner FE et al (2007) NEMURO - a lower trophic level model for the North Pacific marine ecosystem. Ecol Model 202: 12-25. doi:10.1016/j.ecolmodel.2006.08.021 Kobari T, Ikeda T (1999) Vertical distribution, population structure and life cycle of Neocalanus cristatus (Crustacea: Copepoda) in the Oyashio region, with notes on its regional variations. Mar Biol 134: 683-696. doi:10.1007/s002270050584 Kobari T, Ikeda T (2000) Life cycle of Neocalanus species in the Oyashio region. Bull Plankton Soc Japan 47: 129-135.

Kobari T, Ikeda T (2001a) Life cycle of Neocalanus flemingeri (Crustacea: Copepoda) in the Oyashio region, western subarctic Pacific, with notes on its regional variations. Mar Ecol-Prog Ser 209: 243-255.

Kobari T, Ikeda T (2001b) Ontogenetic vertical migration and life cycle of Neocalanus Plumchrus (Crustacea: Copepoda) in the Oyashio region, with notes on regional variations in body sizes. J Plankton Res 23: 287-302. doi:10.1093/plankt/23.3.287

Kobari T, Shinada A, Tsuda A (2003) Functional roles of interzonal migrating mesozooplankton in the western subarctic Pacific. Prog Oceanogr 57: 279-298. doi:10.1016/S0079-6611(03)00102-2 
Liu H, Dagg MJ, Strom S (2005) Grazing by the calanoid copepod Neocalanus cristatus on the microbial food web in the coastal Gulf of Alaska. J Plankton Res 27: 647-662. doi:10.1093/plankt/fbi039

Mackas DL, Tsuda A (1999) Mesozooplankton in the eastern and western subarctic Pacific: community structure, seasonal life histories, and interannual variability. Prog Oceanogr 43: 335-363. doi:10.1016/S0079-6611(99)00012-9 Miller CB, Frost BW, Batchelder HP, Clemons MJ, Conway RE (1984) Life histories of large, grazing copepods in a subarctic ocean gyre: Neocalanus plumchrus, Neocalanus cristatus, and Eucalanus bungii in the northeast Pacific. Prog Oceanogr 13: 201-243. doi:10.1016/0079-6611(84)90009-0 Miller CB, Clemons MJ (1988) Revised life history analysis for large grazing copepods in the subarctic Pacific Ocean. Prog Oceanogr 20: 293-313. doi:10.1016/0079-6611(88)90044-4 Miller CB (1993) Development of large copepods during spring in the Gulf of Alaska. Progr Oceanogr 32: 295-317. doi:10.1016/0079-6611(93)90018-9 Oh B, Terazaki M, Go Y (1993) Biochemical composition of Neocalanus cristatus (Copepoda: Calanoida) in Oyashio and Kuroshio currents: evidence for southward submergence. Bull Mar Res Inst Cheju Natl Univ 17: 13-21. Omori M (1970) Variations of length, weight, respiratory rate, and chemical composition of Calanus cristatus in relation to its food and feeding. In: Steele JH (eds) Marine food chains. Oliver and Boyd, Edinburgh, pp. 113-126.

Saito H, Tsuda A (2000) Egg production and early development of the subarctic copepods Neocalanus cristatus, $N$. plumchrus and N. flemingeri. Deep Sea Res I 47: 2141-2158. doi:10.1016/S0967-0637(00)00017-0

Shinada A, Ikeda T, Ban S, Tsuda A (2001) Seasonal dynamics of planktonic food chain in the Oyashio region, western subarctic Pacific. J Plankton Res 23: 12371248. doi:10.1093/plankt/23.11.1237

Terui T, Kishi MJ (2008) Population dynamics model of Copepoda (Neocalanus cristatus) in the northwestern subarctic Pacific. Ecol Model 215: 77-88. doi:10.1016/j.ecolmodel.2008.02.012 Tsuda A, Sugisaki H (1994) In situ grazing rate of the copepod population in the western subarctic North Pacific during spring. Mar Biol 120: 203-210. doi:10.1007/BF00349680 
Vidal J, Whitledge TE (1982) Rates of metabolism of planktonic crustaceans as related to body weight and temperature of habitat. J Plankton Res 4: 77-84. doi:10.1093/plankt/4.1.77

Vidal J, Smith SL (1986) Biomass, growth, and development of populations of herbivorous zooplankton in the southeastern Bering Sea during spring. Deep Sea Res A 33: 523-556. doi:10.1016/0198-0149(86)90129-9

Woods JD, Onken R (1982) Diurnal variation and primary production in the ocean preliminary results of a Lagrangian ensemble model. J Plankton Res 4: 735756. doi:10.1093/plankt/4.3.735

Yamaguchi A, Onishi Y, Kawai M, Omata A, Kaneda M, Ikeda T (2010) Diel and ontogenetic variations in vertical distributions of large grazing copepods during the spring phytoplankton bloom in the Oyashio region. Deep Sea Res II 57: 16911702. doi:10.1016/j.dsr2.2010.03.013 


\section{Figure Caption}

Fig. 1: Conceptual diagram of the coupled model. Bold black lines are the interaction between NEMURO and the LEM. The LEM has cohorts list, which is divided by its birth date. Each cohort has information on birth date, weight, stage, age and number. The LEM been coupled with a box model of NEMURO.

Fig. 2: Idealized seasonal change in (a) sea surface temperature that is used as the surface boundary condition, (b) solar radiation, and (c) simulated seasonal variation in the mixed layer thickness.

Fig. 3: Relationship between each weight and excretion. Shown is proportion of excretion. Solid line is for $2{ }^{\circ} \mathrm{C}$, dot line is for $4^{\circ} \mathrm{C}$, and dash line is for $6^{\circ} \mathrm{C}$.

Fig. 4: The last one year of the simulation for NEMURO with LEM in the surface layer. The biomass of (a) PS and PL, (b) ZS, ZL, ZP, and the sum of copepodites biomass.

Fig. 5: Abundance population density of (a) Eggs, Nauplii, Solids, and Adults in the deep box. Left vertical axis means abundance of Solids and Adults. Right vertical axis means Eggs and Nauplii. (b) Copepodite stages in the surface box.

Fig. 6: Biomass of each stage of simulated N. cristatus.

Fig. 7: Growth rate of four population particles; (a) born on February 22th, (b) born on March 3rd, (c) born on March 17th, and (d) born on April 7th.

Fig. 8: The period of copepodite stages for each birth date. Black bars are for the first group, gray bars are for the second group, and the white bars are for the third group.

Fig. 9: The sensitivity of the time dependent features to temperature. (a) The biomass of PL, (b) total biomass of copepodite stages, and (c) the growth rate of the particle born on February 22th. Solid line is for standard condition, dotted line is for $1^{\circ} \mathrm{C}$ increased case, and dashed line is for $1^{\circ} \mathrm{C}$ decreased case.

Fig. 10: The sensitivity of growth of different cohorts to max ingestion rate; (a) born on February 22th, (b) born on March 3rd, (c) born on March 17th, and (d) born on April 7th. Solid line is for standard ingestion rate, dashed line is for 1.5 times, and dotted line is for 2 times larger case. The number on top of line is the duration of copepodite stages. 

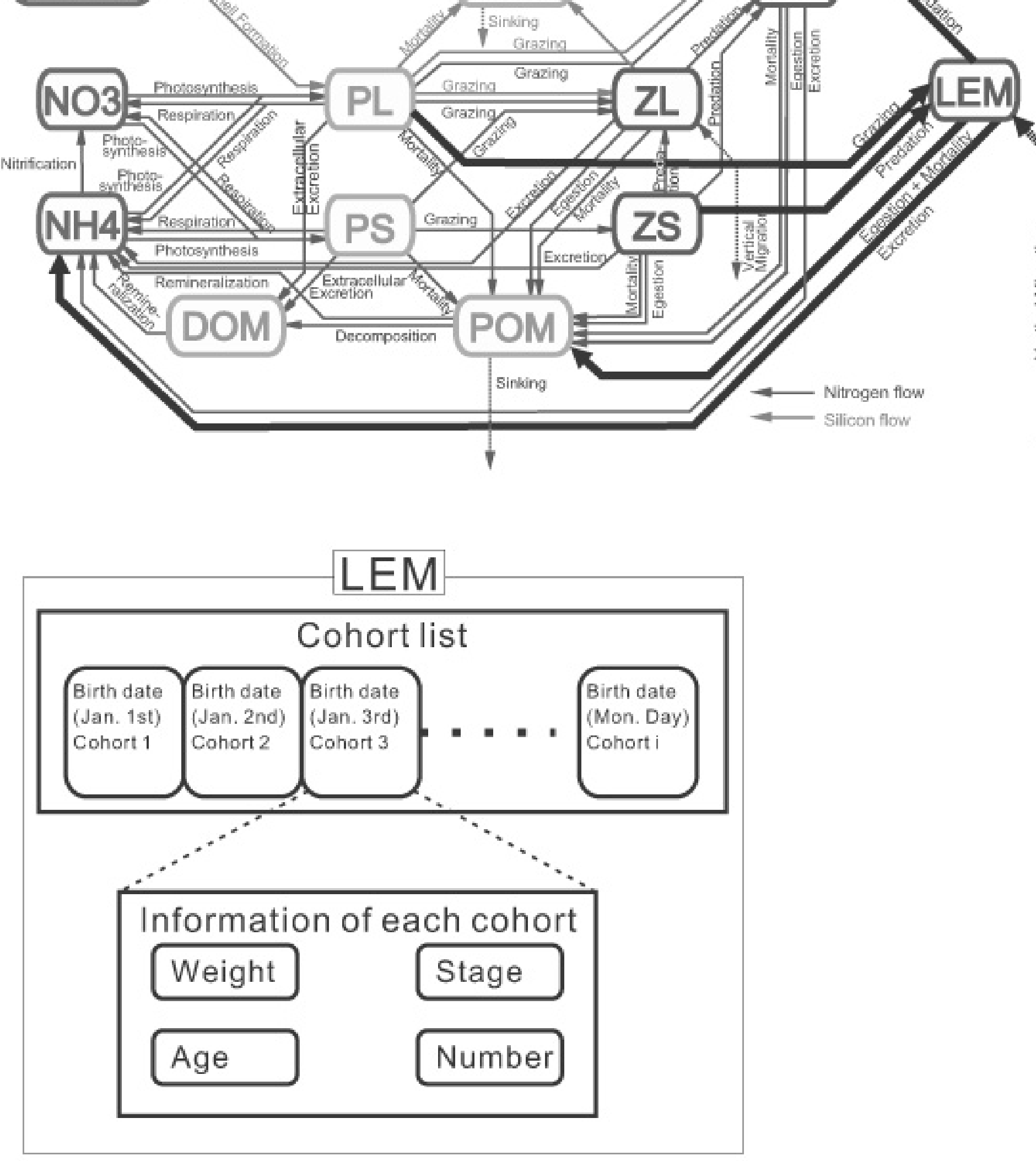

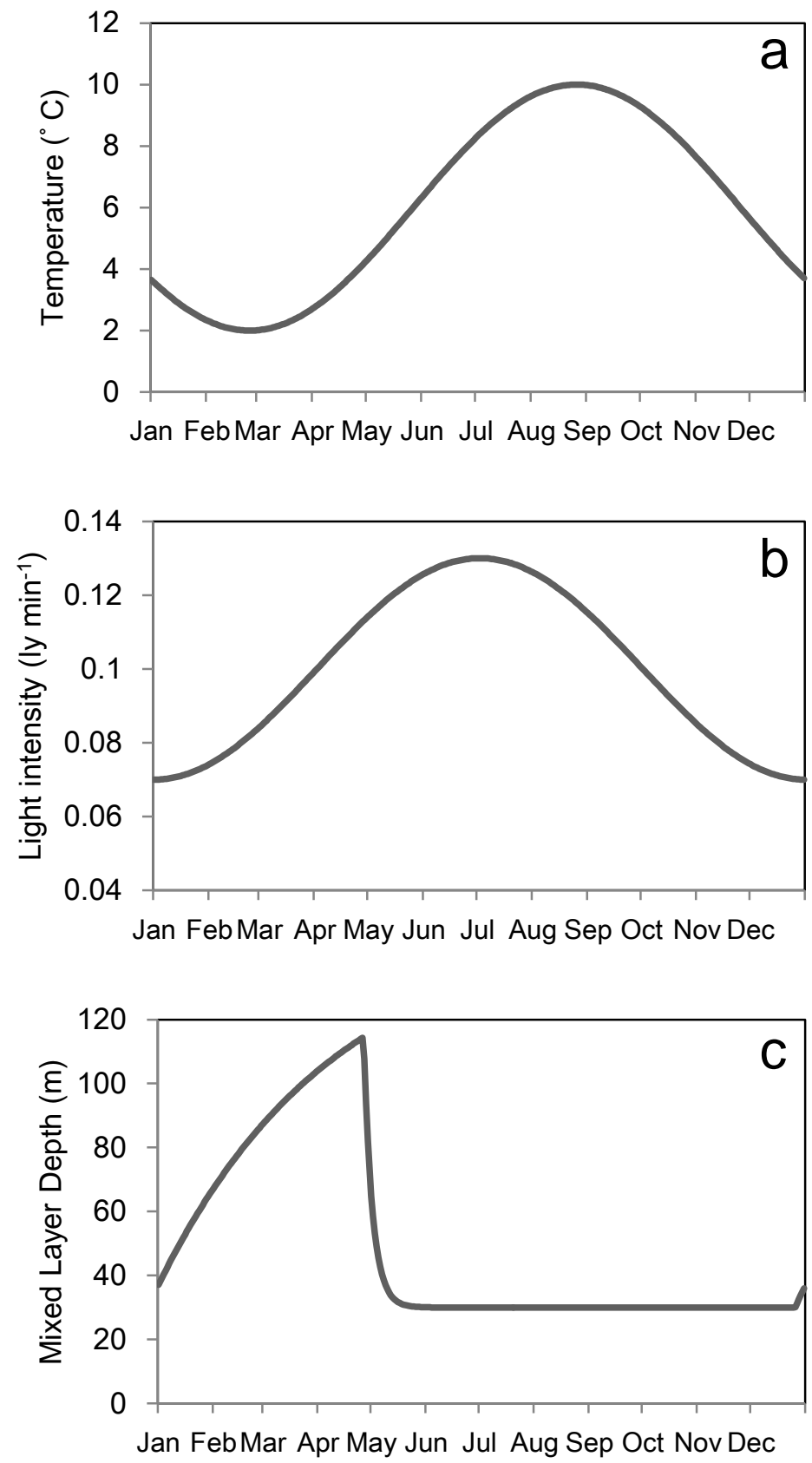

Figure 2 


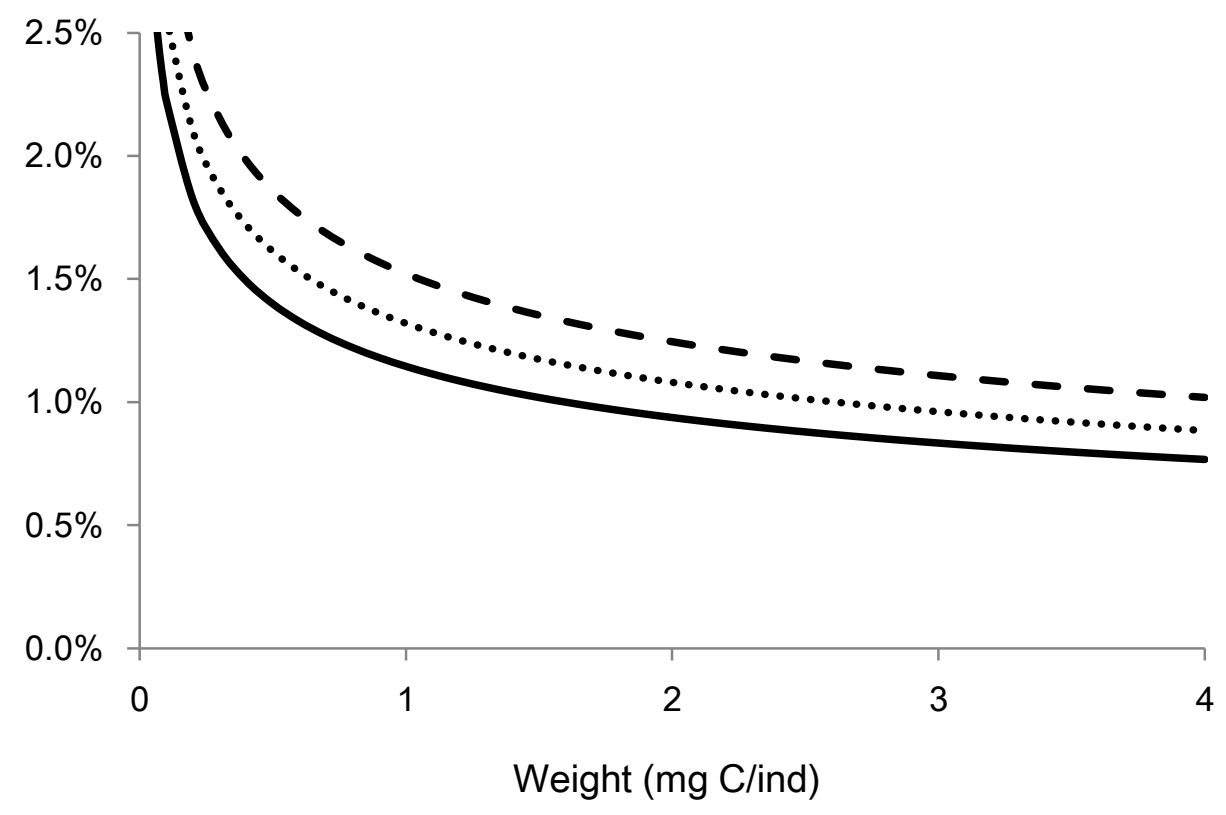

Figure 3 

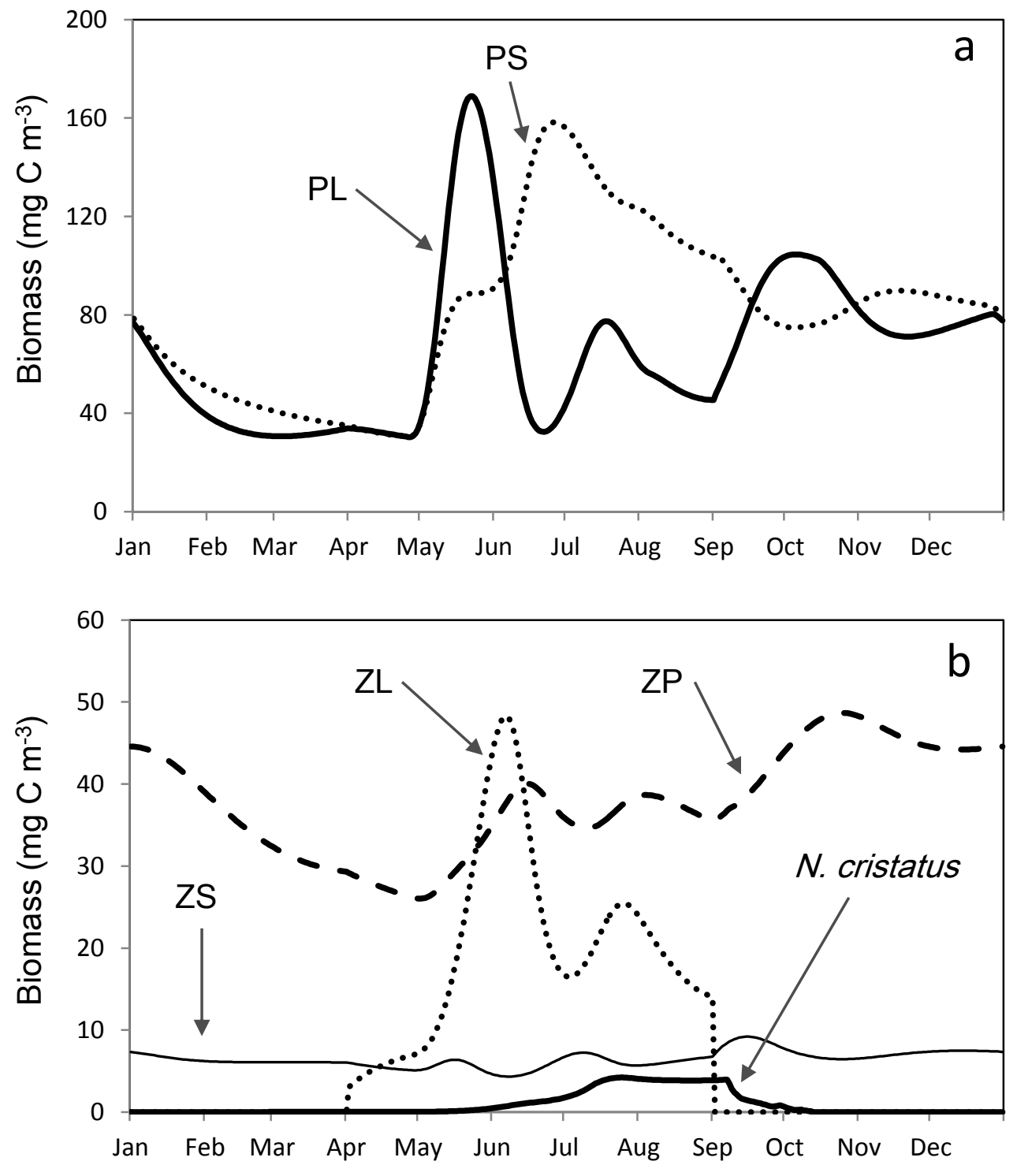

Figure 4 

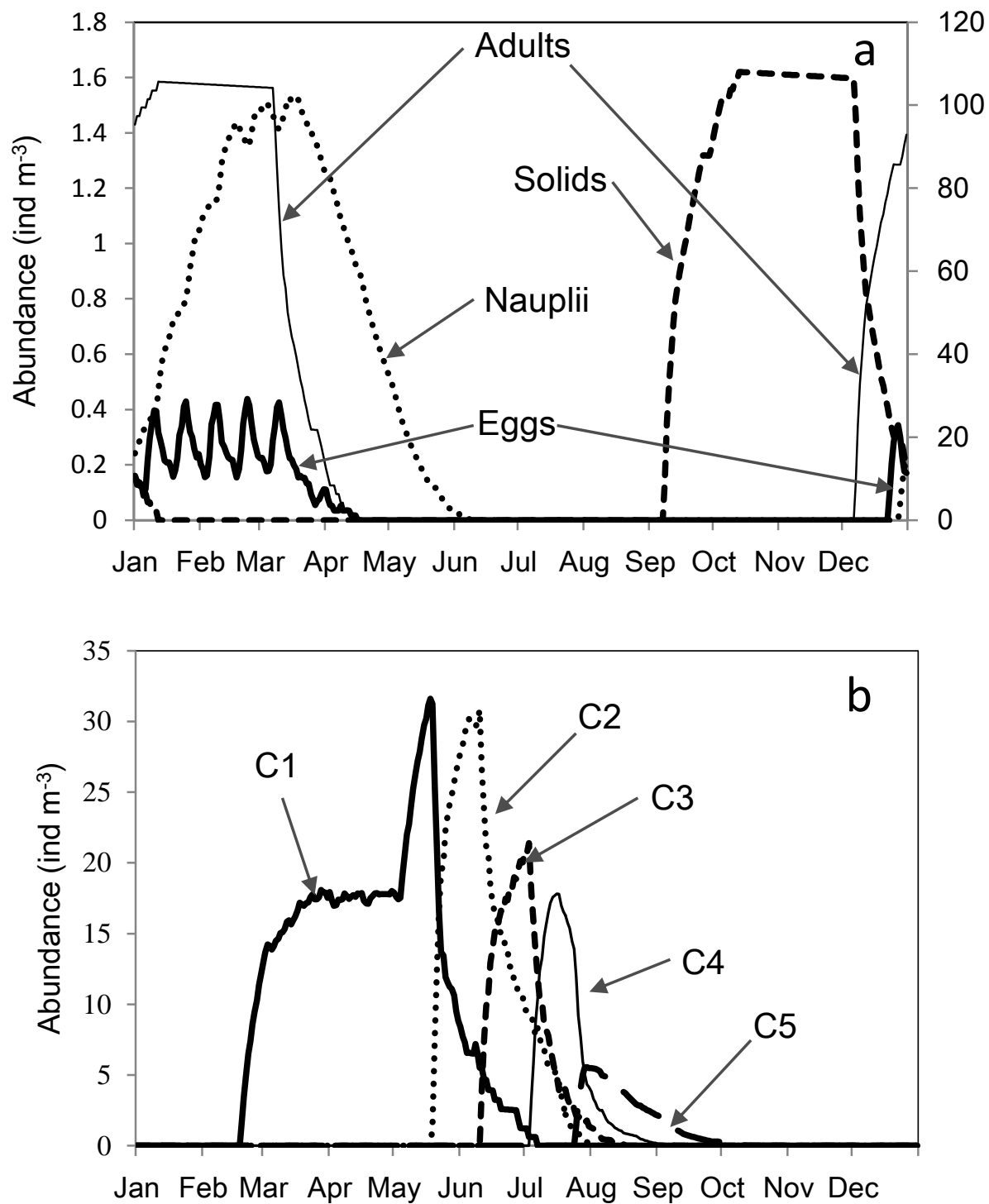

Figure 5 


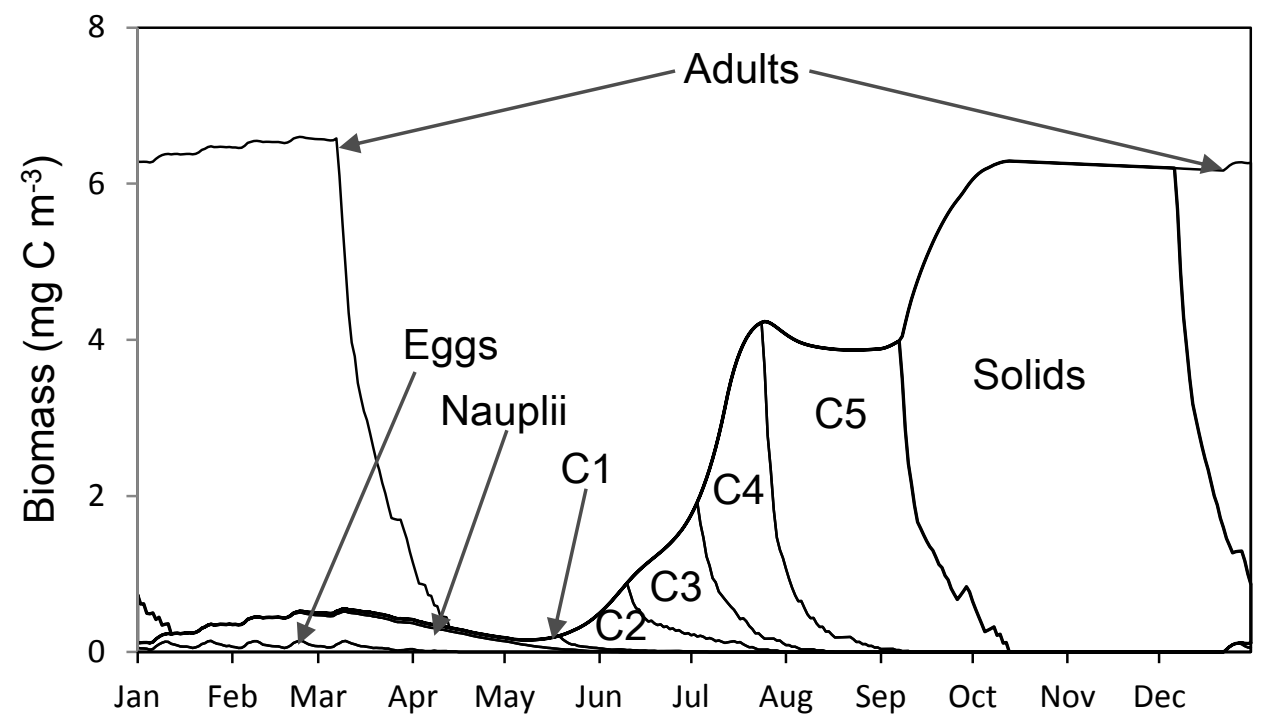

Figure 6 

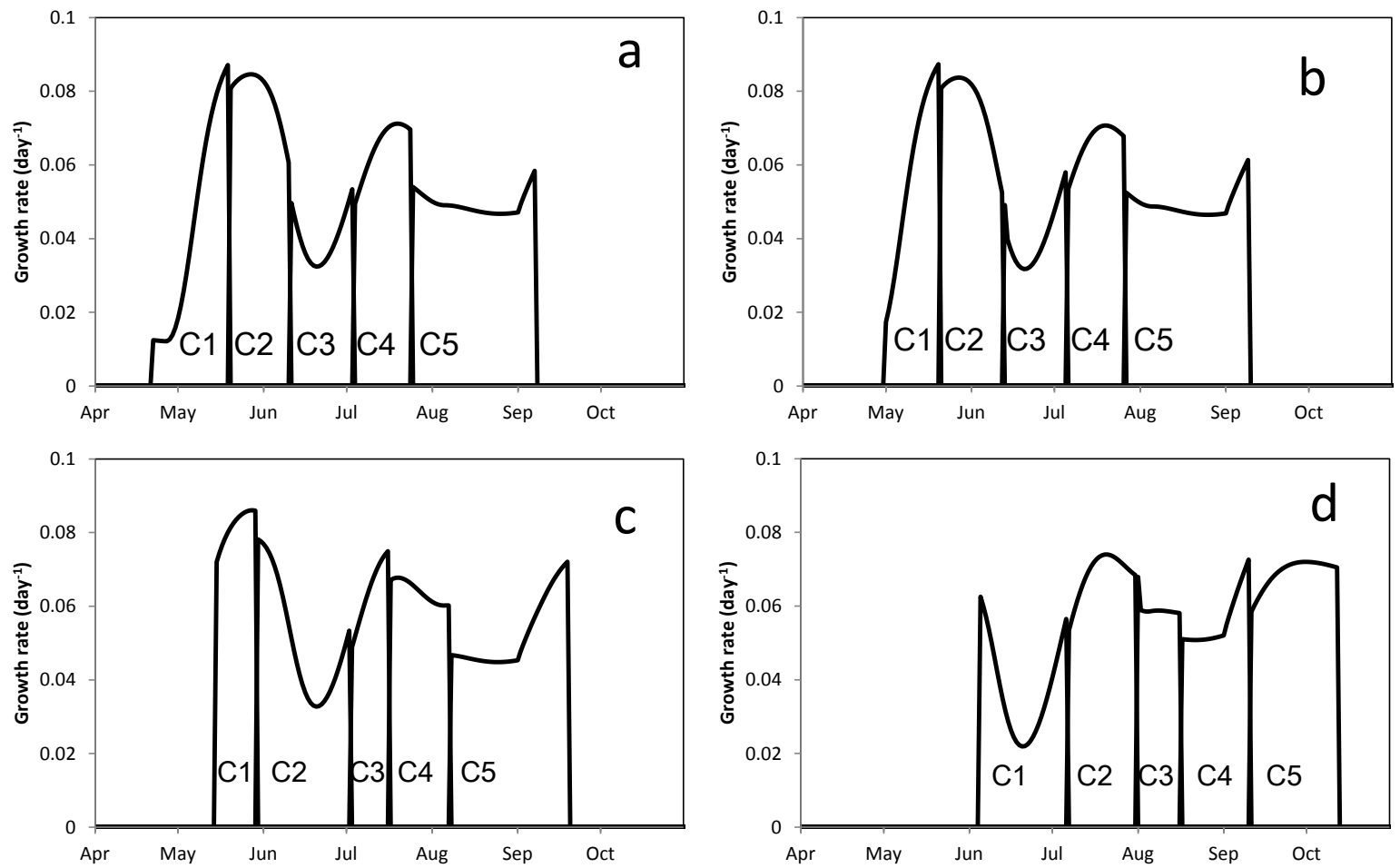

Figure 7 


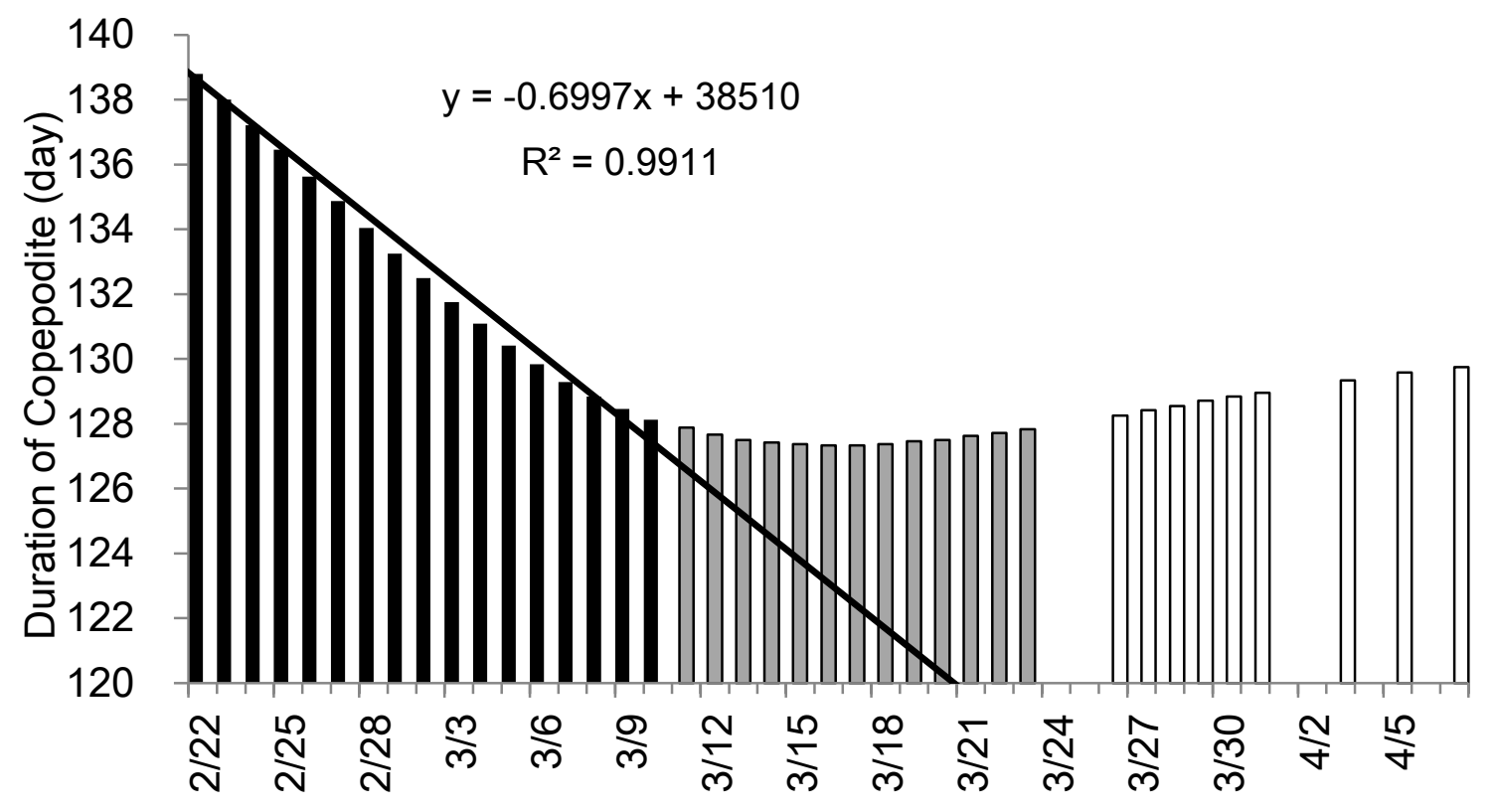

Figure 8 

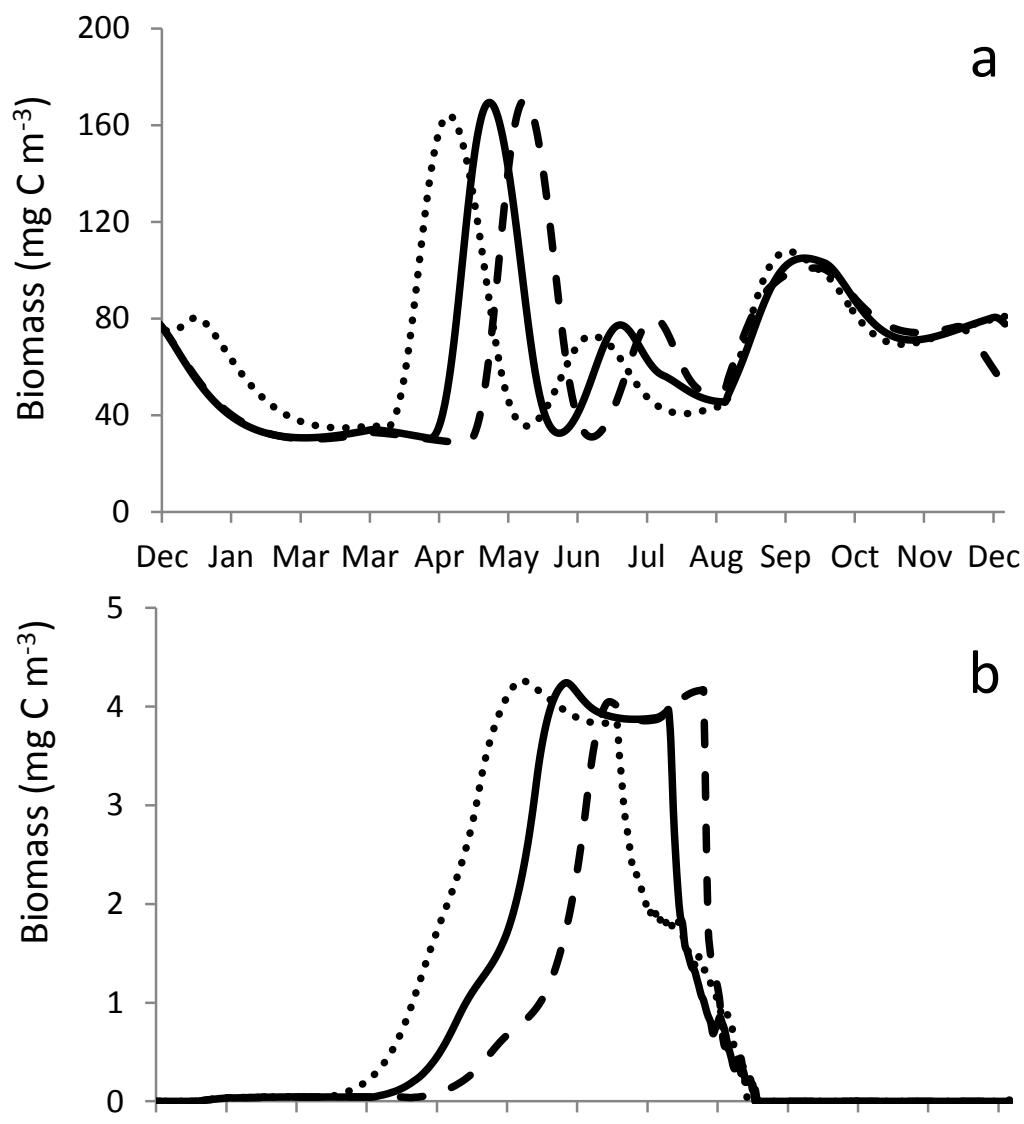

Dec Jan Mar Mar Apr May Jun Jul Aug Sep Oct Nov Dec

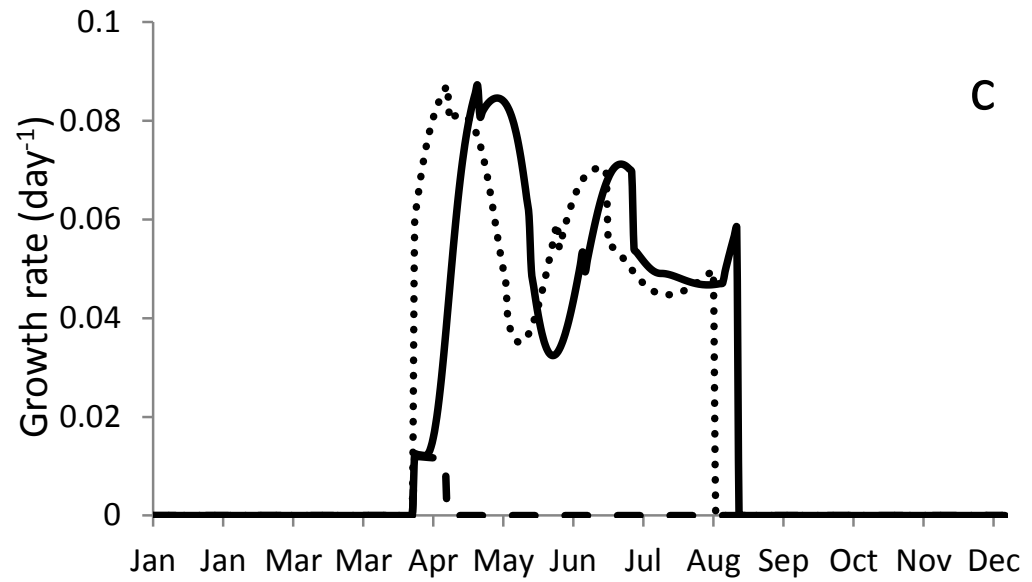

Figure 9 

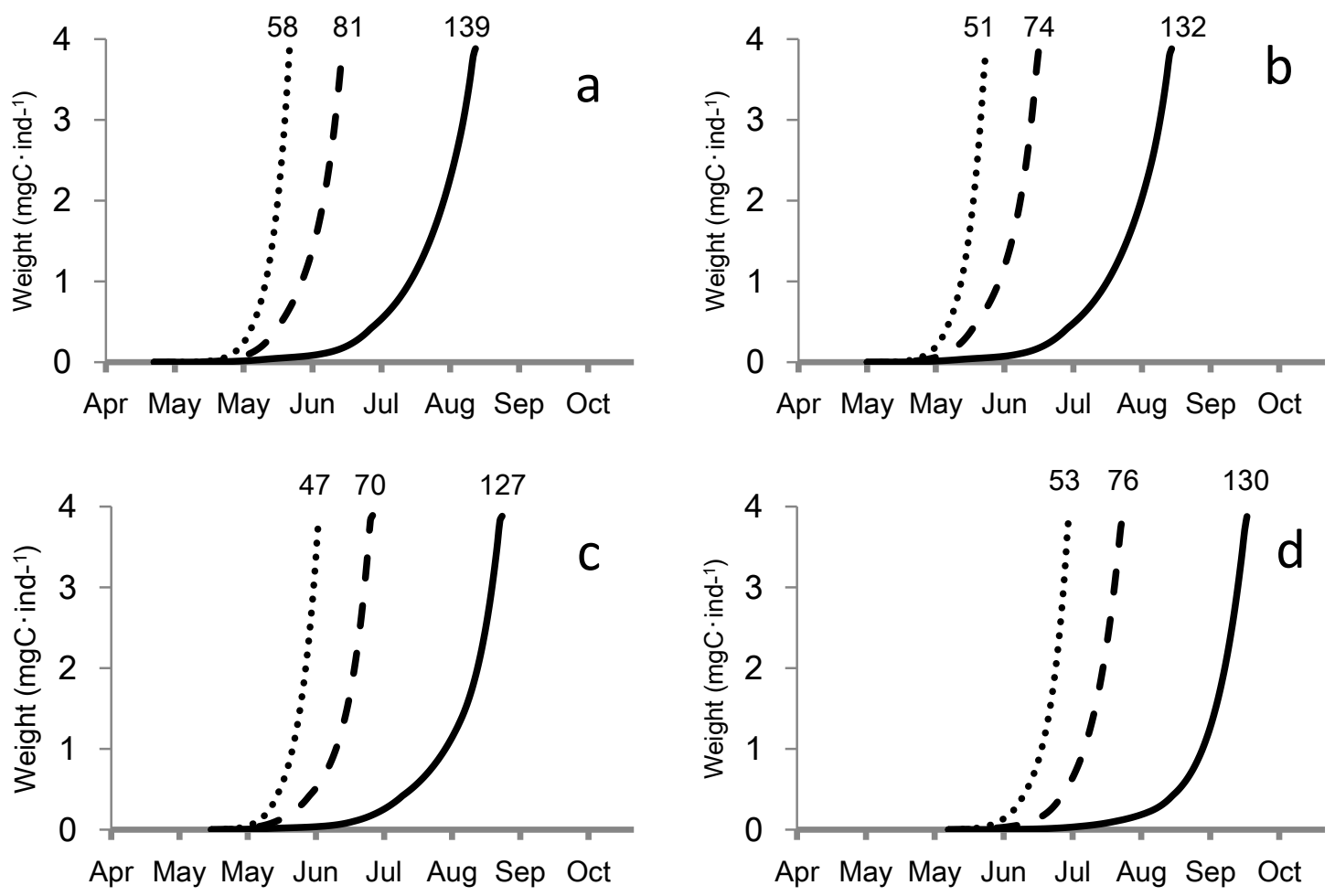

Figure 10 


\section{Table Contents}

Table 1: Mathematical formulations of growing used in a Lagrangian cohort. i: each cohort number, T: temperature, food: PL or ZS in the NEMURO, $\mathrm{W}_{\mathrm{i}}$ : individual weight of cohort $\mathrm{i}, \mathrm{f} 1$ : Ivlev function, f2: Q10 low, nd: nondimensional , and P1 to P6: biological parameters (see their definitions in Table 2).

Table 2: Parameters used in the Lagrangian ensemble model. nd: nondimensional, MorR: constant mortality ratio, IW: initial weight, X: critical weight for molting, and arrows indicate same value as to the side.

Table 3: Ecological conditions and model setting in each stage.

Talbe 4: Processes coupling the zooplankton population dynamics model (LEM) to the other components of the NEMURO. Total biomass of these processes is the sum of only copepodites cohort. i: each population number; $\mathrm{W}_{\mathrm{i}}$ : weight; $\mathrm{N}_{\mathrm{i}}$ : abundance.

Table 5: The monthly mean PL, ZS, temperature, and growth rate of each copepodite stage. These growth rates are calculated for the period when population particles are alive.

Table 6: History of growth of typical cohort in the LEM. Next Year - NY 


\begin{tabular}{|c|c|c|}
\hline Process & Units & Formulation \\
\hline Ingestion & mg C ind ${ }^{-1}$ day $^{-1}$ & Ingestion $_{\mathrm{i}}=\mathrm{f} 1 \times \mathrm{f} 2 \times \mathrm{W}_{\mathrm{i}}$ \\
\hline Food concentration response & day $^{-1}$ & $\mathrm{f} 1=\mathrm{P} 1 \times(1.0-\exp (\mathrm{P} 5 \times(\mathrm{P} 2-$ food $)))$ \\
\hline Temperature response & nd & $\mathrm{f} 2=\mathrm{P} 4 \times \exp (\mathrm{P} 3 \times \mathrm{T})$ \\
\hline Egestion & mg C ind ${ }^{-1}$ day $^{-1}$ & Egestion $_{i}=(1-\mathrm{P} 6) \times$ Ingestion $_{\mathrm{i}}$ \\
\hline $\begin{array}{l}\text { Excretion of ammonia } \\
\text { Excretion }\end{array}$ & $\begin{array}{l}\mu \mathrm{g} \mathrm{N} \text { ind }{ }^{-1} \mathrm{~h}^{-1} \\
\mathrm{mg} \mathrm{C} \text { ind }^{-1} \text { day }^{-1}\end{array}$ & $\begin{array}{l}\ln (\mathrm{AE})=-2.769+0.711 \ln \left(\mathrm{W}_{\mathrm{i}}\right)+0.071 \times \mathrm{T} \\
\text { Excretion }_{\mathrm{i}}=\mathrm{AE} \times 6.6 \times 24 \div 1000 .\end{array}$ \\
\hline
\end{tabular}




\begin{tabular}{|c|c|c|c|c|c|c|c|c|c|c|c|}
\hline Stage number & & 1 & 2 & 3 & 4 & 5 & 6 & 7 & 8 & 9 & References \\
\hline Parameters & Units & Egg & Nauplii & $\mathrm{C} 1$ & $\mathrm{C} 2$ & $\mathrm{C} 3$ & $\mathrm{C} 4$ & C5 & Solid & Adult & \\
\hline \multicolumn{12}{|l|}{ Ingestion } \\
\hline Max growth rate & day $^{-1}$ & & & 0.079 & 0.078 & 0.077 & 0.065 & 0.047 & & & Vidal and Smith (1986) \\
\hline P1 & day $^{-1}$ & & & 0.222 & 0.197 & $0 . .170$ & 0.147 & 0.116 & & & $\begin{array}{l}\text { Ikeda and Motoda, (1975); } \\
\text { Vidal and Smith (1986) }\end{array}$ \\
\hline P2 & $\mathrm{mg} \mathrm{C} \mathrm{m}^{-3}$ & & & 0 & $\leftarrow$ & $\leftarrow$ & $\leftarrow$ & $\leftarrow$ & & & Liu et al. (2005) \\
\hline P3 & nd & & & 0.056 & $\leftarrow$ & $\leftarrow$ & $\leftarrow$ & $\leftarrow$ & & & Vidal and Whitledge (1982) \\
\hline P4 & nd & & & 0.714 & $\leftarrow$ & $\leftarrow$ & $\leftarrow$ & $\leftarrow$ & & & Vidal and Whitledge (1982) \\
\hline P5 & $\mathrm{m}^{3} \mathrm{mg} \mathrm{C^{-1 }}$ & & & 0.015 & $\leftarrow$ & $\leftarrow$ & $\leftarrow$ & $\leftarrow$ & & & \\
\hline \multicolumn{12}{|l|}{ Egestion } \\
\hline P6 & nd & & & 0.7 & $\leftarrow$ & $\leftarrow$ & $\leftarrow$ & $\leftarrow$ & & & Kobari et al. (2003) \\
\hline \multicolumn{12}{|l|}{ Reproduction } \\
\hline Amount of eggs & eggs ind ${ }^{-1}$ & & & & & & & & & 76 & Saito and Tsuda (2000) \\
\hline Age & & & & & & & & & & & Saito and Tsuda (2000) \\
\hline The period of day & day & 5.7 & 53.2 & & & & & & 90.0 & 91.1 & Saito and Tsuda (2000) \\
\hline Laying eggs interval & day & & & & & & & & & 14.7 & Saito and Tsuda (2000) \\
\hline Starvation day & day & & & 14 & $\leftarrow$ & $\leftarrow$ & $\leftarrow$ & $\leftarrow$ & & & \\
\hline \multicolumn{12}{|l|}{ Growth \& Mortality } \\
\hline Critical growth rate & day $^{-1}$ & & & 0.03 & $\leftarrow$ & $\leftarrow$ & $\leftarrow$ & $\leftarrow$ & & & Dagg (1993) \\
\hline MorR & day $^{-1}$ & 0.0065 & $\leftarrow$ & $\leftarrow$ & $\leftarrow$ & $\leftarrow$ & $\leftarrow$ & $\leftarrow$ & $\leftarrow$ & $\leftarrow$ & Mackas and Tsuda (1999) \\
\hline \multicolumn{12}{|l|}{ Weight } \\
\hline IW & $\mathrm{mg} \mathrm{C}$ ind $^{-1}$ & 0.005 & 0.004 & 0.002 & 0.007 & 0.042 & 0.106 & 0.422 & 3.877 & 3.877 & Kobari et al. (2003) \\
\hline $\mathrm{X}$ & $\operatorname{mg~C}$ ind $^{-1}$ & & & 0.007 & 0.042 & 0.106 & 0.422 & 3.877 & & & \\
\hline
\end{tabular}




\begin{tabular}{ccccccc}
\hline Stage & Living depth & Temp. $\left({ }^{\circ} \mathrm{C}\right)$ & Starvation & Predation by ZP & Feeding & $\begin{array}{c}\text { Development } \\
\text { mechanism }\end{array}$ \\
\hline Eggs & deep box & 2 & no & no & no & fixed duration \\
Nauplii & deep box & 2 & no & no & no & fixed duration \\
C1 & surface box & $2-10$ & yes & yes & PL, ZS & depend on growth \\
C2 & surface box & $2-10$ & yes & yes & PL, ZS & depend on growth \\
C3 & surface box & $2-10$ & yes & yes & PL, ZS & depend on growth \\
C4 & surface box & $2-10$ & yes & yes & PL, ZS & depend on growth \\
C5 & surface box & $2-10$ & yes & yes & PL, ZS & depend on growth \\
Solids & deep box & 2 & no & no & no & fixed duration \\
Adults & deep box & 2 & no & no & no & fixed duration \\
\hline
\end{tabular}




\begin{tabular}{ll}
\hline Process & Formulation \\
\hline Grazing of ZS to Neocalanus & GRZS2LEM $=\sum_{\mathrm{i}=1}^{\mathrm{n}}\left(\right.$ Ingestion $\left._{\mathrm{i}, \mathrm{ZS}} \times \mathrm{N}_{\mathrm{i}}\right)$ \\
Grazing of PL to Neocalanus & GRPL2LEM $=\sum_{\mathrm{i}=1}^{\mathrm{n}}\left(\right.$ Ingestioni $\left._{, \mathrm{PL}} \times \mathrm{Ni}\right)$ \\
Total egestion material & EgeLEM $=\sum_{\mathrm{i}=1}^{\mathrm{n}}\left(\right.$ Egestion $\left._{\mathrm{i}, \mathrm{PL}} \times \mathrm{Ni}\right)+\sum_{\mathrm{i}=1}^{\mathrm{n}}\left(\right.$ Egestion $\left._{\mathrm{i}, \mathrm{ZS}} \times \mathrm{Ni}\right)$ \\
Total excretion material & ExcLEM $=\sum_{\mathrm{i}=1}^{\mathrm{n}}\left(\right.$ Excretion $\left._{\mathrm{i}} \times \mathrm{Ni}\right)$ \\
Total dead zooplankton & MorLEM $=\sum_{\mathrm{i}=1}^{\mathrm{n}}\left(\right.$ Mortality $\left._{\mathrm{i}} \times \mathrm{Ni} \times \mathrm{W}_{\mathrm{i}}\right)$ \\
\hline
\end{tabular}




\begin{tabular}{|c|c|c|c|c|c|c|c|c|}
\hline \multirow[b]{2}{*}{ Month } & \multicolumn{5}{|c|}{ Growth Rate $\left(\right.$ day $\left.^{-1}\right)$} & \multicolumn{2}{|c|}{ Biomass ( $\mathrm{mg} \mathrm{C} \mathrm{m}^{-3}$ ) } & \multirow[t]{2}{*}{ Temperature $\left({ }^{\circ} \mathrm{C}\right)$} \\
\hline & $\mathrm{C} 1$ & $\mathrm{C} 2$ & $\mathrm{C} 3$ & $\mathrm{C} 4$ & $\mathrm{C} 5$ & PL & $\mathrm{ZS}$ & \\
\hline April & $0.013 \pm 0.001$ & - & - & - & - & $32.2 \pm 1.2$ & $5.5 \pm 0.3$ & $3.4 \pm 0.5$ \\
\hline May & $0.068 \pm 0.020$ & $0.082 \pm 0.001$ & - & - & - & $121.6 \pm 45.7$ & $5.7 \pm 0.5$ & $5.3 \pm 0.6$ \\
\hline June & $0.051 \pm 0.019$ & $0.052 \pm 0.018$ & $0.037 \pm 0.005$ & - & - & $58.9 \pm 31.4$ & $5.0 \pm 0.7$ & $7.3 \pm 0.6$ \\
\hline July & $0.047 \pm 0.005$ & $0.065 \pm 0.011$ & $0.062 \pm 0.009$ & $0.066 \pm 0.005$ & $0.052 \pm 0.003$ & $66.3 \pm 9.9$ & $6.6 \pm 0.6$ & $9.0 \pm 0.4$ \\
\hline August & - & - & $0.060 \pm 0.002$ & $0.056 \pm 0.003$ & $0.047 \pm 0.002$ & $50.9 \pm 4.4$ & $6.2 \pm 0.3$ & $9.9 \pm 0.1$ \\
\hline September & - & - & - & $0.061 \pm 0.006$ & $0.061 \pm 0.009$ & $78.3 \pm 18.6$ & $8.5 \pm 0.6$ & $9.7 \pm 0.2$ \\
\hline October & - & - & - & - & $0.072 \pm 0.001$ & $98.1 \pm 7.1$ & $6.8 \pm 0.4$ & $8.5 \pm 0.5$ \\
\hline
\end{tabular}




\begin{tabular}{ccccccc}
\hline Birth date & $\begin{array}{c}\text { Growth date } \\
\text { to C1 }\end{array}$ & $\begin{array}{c}\text { Growth date } \\
\text { to Solid }\end{array}$ & $\begin{array}{c}\text { Days of } \\
\text { copepodite }\end{array}$ & $\begin{array}{c}\text { Starting date of } \\
\text { laying egg }\end{array}$ & Date of death & $\begin{array}{c}\text { Mean growth rate } \\
\left(\text { day }^{-1}\right)\end{array}$ \\
\hline $1 / 1$ & $2 / 28$ & - & 14 & - & $3 / 14$ & 0.014 \\
$2 / 21$ & $4 / 19$ & - & 14 & - & $5 / 3$ & 0.015 \\
$2 / 22$ & $4 / 20$ & $9 / 7$ & 139 & $12 / 21$ & $3 / 7(\mathrm{NY})$ & 0.053 \\
$3 / 3$ & $4 / 29$ & $9 / 9$ & 132 & $12 / 23$ & $3 / 9(\mathrm{NY})$ & 0.056 \\
$3 / 17$ & $5 / 14$ & $9 / 19$ & 127 & $1 / 1(\mathrm{NY})$ & $3 / 19(\mathrm{NY})$ & 0.058 \\
$4 / 7$ & $6 / 4$ & $10 / 12$ & 130 & $1 / 25(\mathrm{NY})$ & $4 / 11(\mathrm{NY})$ & 0.057 \\
\hline
\end{tabular}

